\title{
Evaluation of SCIAMACHY Oxygen A band cloud heights using Cloudnet measurements
}

\author{
P. Wang and P. Stammes \\ Royal Netherlands Meteorological Institute (KNMI), De Bilt, the Netherlands \\ Correspondence to: P. Wang (ping.wang@knmi.nl)
}

Received: 16 July 2013 - Published in Atmos. Meas. Tech. Discuss.: 1 October 2013

Revised: 31 March 2014 - Accepted: 1 April 2014 - Published: 19 May 2014

\begin{abstract}
Two SCIAMACHY (SCanning Imaging Absorption spectroMeter for Atmospheric CHartographY) $\mathrm{O}_{2} \mathrm{~A}$ band cloud height products are evaluated using ground-based radar/lidar measurements between January 2003 and December 2011. The products are the ESA (European Space Agency) Level 2 (L2) version 5.02 cloud top height and the FRESCO (Fast Retrieval Scheme for Clouds from the Oxygen A band) version 6 cloud height. The radar/lidar profiles are obtained at the Cloudnet sites of Cabauw and Lindenberg, and are averaged for $1 \mathrm{~h}$ centered at the SCIAMACHY overpass time. In total we have 217 cases of single-layer clouds and 204 cases of multilayer clouds. We find that the ESA L2 cloud top height has a better agreement with the Cloudnet cloud top height than the Cloudnet cloud middle height. The ESA L2 cloud top height is on average $0.4 \mathrm{~km}$ higher than the Cloudnet cloud top height, with a standard deviation of $3.1 \mathrm{~km}$. The FRESCO cloud height is closer to the Cloudnet cloud middle height than the Cloudnet cloud top height. The mean difference between the FRESCO cloud height and the Cloudnet cloud middle height is $-0.1 \mathrm{~km}$ with a standard deviation of $1.9 \mathrm{~km}$. The ESA L2 cloud top height is higher than the FRESCO cloud height. The differences between the SCIAMACHY cloud (top) height and the Cloudnet cloud top height are linked to cloud optical thickness. The SCIAMACHY cloud height products are further compared to the Cloudnet cloud top height and the Cloudnet cloud middle height in $1 \mathrm{~km}$ bins. For single-layer clouds, the difference between the ESA L2 cloud top height and the Cloudnet cloud top height is less than $1 \mathrm{~km}$ for each cloud bin at $3-7 \mathrm{~km}$. The difference between the FRESCO cloud height and the Cloudnet cloud middle height is less than $1 \mathrm{~km}$ for each cloud bin at $0-6 \mathrm{~km}$. The results are similar for multilayer clouds, but the percentage of cases having a bias within
\end{abstract}

$1 \mathrm{~km}$ is smaller than for single-layer clouds. We may conclude that the FRESCO cloud height is accurate for low and middle level clouds, whereas the ESA L2 cloud top height is more accurate for middle level clouds. Both products are less accurate for high clouds.

\section{Introduction}

The SCIAMACHY (SCanning Imaging Absorption spectroMeter for Atmospheric CHartographY) instrument had performed measurements of trace gases, clouds and aerosols for almost 10 years (2002-2012) when Envisat (Environmental Satellite) and its payload stopped operations unexpectedly on 8 April 2012. SCIAMACHY measured the reflected Earth radiance and incident solar irradiance at the top of the atmosphere in the $240-1750 \mathrm{~nm}$ wavelength range and selected regions between 2000 and $2400 \mathrm{~nm}$ at a spectral resolution of 0.2-1.5 nm (Bovensmann et al., 1999). It is a challenge to retrieve cloud information from SCIAMACHY because of its large pixel size. In an area of $60 \mathrm{~km} \times 30 \mathrm{~km}$, which is the typical SCIAMACHY pixel size for the $\mathrm{O}_{2} \mathrm{~A}$ band wavelength range, clouds are often multilayer, inhomogeneous, or broken.

Clouds affect trace gas retrievals from SCIAMACHY and other instruments, because of shielding of the lower atmosphere, enhanced sensitivity above clouds (albedo effect), and in-cloud absorption. Cloud top height, cloud geometric thickness, cloud fraction, cloud optical thickness, and number of cloud layers are all important for cloud correction of trace gas retrievals, especially for trace gases in the troposphere (Boersma et al., 2004; Bucsela et al., 2006; Stammes et al., 2008). Regarding climate studies, clouds 
play an important role in the energy and water cycle of Earth. A change of only about $1 \%$ in global cloudiness can either mask or double the effect that a decade's worth of greenhouse-gas emissions have on the amount of Earth's heat lost to space (Wielicki et al., 2005).

Within the Global Energy and Water Experiment (GEWEX) cloud assessment project (Stubenrauch et al., 2013) various satellite-derived monthly mean global cloud products were compared. From this intercomparison of cloud observations from multispectral imagers, multiangle multispectral imagers, IR (infrared) sounders and lidar, Stubenrauch et al. (2013) concluded that cloud top height can be accurately determined from space with lidar (e.g., CALIPSO; Winker et al., 2009) whereas passive remote sensing provides a "radiative height" (apart from the MISR - Multi-angle Imaging SpectroRadiometer - stereoscopic height retrieval). In general, the "radiative height" lies near the middle between cloud top and "apparent" cloud base. They reported that the cloud height determined via $\mathrm{O}_{2}$ absorption from the POLDER (POLarization and Directionality of the Earth's Reflectances) instrument corresponded to a location even deeper inside the cloud (Ferlay et al., 2010; Desmons et al., 2013). Note that it does not mean that the cloud top height cannot be derived from the $\mathrm{O}_{2}$ absorption band (see the results in this paper). The heightstratified cloud amount was determined for high, middle and low clouds, with separation levels at 440 and $680 \mathrm{hPa}$, corresponding to altitudes of about 6 and $3 \mathrm{~km}$, respectively. Stubenrauch et al. (2013) found that about $42 \%$ of all clouds are high-level clouds with optical thickness $>0.1$; the fraction of high clouds decreases to $20 \%$ when considering only clouds with optical thickness $>2$. About $16 \%( \pm 5 \%)$ of all clouds correspond to midlevel clouds with no other clouds above. About $42 \%( \pm 5 \%)$ of all clouds are single-layer lowlevel clouds. When including low-level clouds underneath semi-transparent higher level clouds, about $60 \%$ of all clouds correspond to low-level clouds.

The radar/lidar combination can be considered currently the most accurate remote sensing tool to measure cloud vertical extent. However, these active instruments have necessarily a very small field of view (FOV). Therefore, most of the time passive satellite instruments (imaging radiometers or spectrometers) and active satellite-based or groundbased instruments observe different (parts of) clouds. The comparison between cloud top height from passive satellite instruments and radar/lidar instruments requires a good temporal and spatial matching. The Equator overpass time of CALIPSO (Cloud-Aerosol Lidar and Infrared Pathfinder Satellite Observation) and Cloudsat is close to 13:30 LT (local time). The time difference between CALIPSO/Cloudsat and SCIAMACHY measurements is often too large $(3.5 \mathrm{~h})$ to allow observing similar cloudy scenes. Most cloud systems are too variable to remain constant in this time period. Consequently, we do not use the CALIPSO and Cloudsat cloud products for the evaluation of the SCIAMACHY cloud products.

We used the ground-based radar/lidar cloud height data set from the Cloudnet project. The Cloudnet project (Illingworth et al., 2007) operates a network of ground stations to continuously monitor cloud-related variables over multiyear time periods. The remote sensing sites of Cabauw and Lindenberg are two Cloudnet sites, which are equipped with suitable ground-based remote sensing instruments, such as radar, lidar, and microwave radiometer, to measure cloud and aerosol profiles operationally (www.cloud-net.org). The time period of the Cloudnet products covers the whole lifetime of SCIAMACHY (2002-2012), which provides a unique opportunity to validate the whole time series of SCIAMACHY cloud height products.

The Fast Retrieval Scheme for Clouds from the Oxygen A band (FRESCO) is an operational cloud retrieval algorithm developed by Koelemeijer et al. (2001) and Wang et al. (2008), which derives effective cloud fraction and cloud height from GOME, SCIAMACHY and GOME- $2 \mathrm{O}_{2}$ A band observations and provides near-real-time data to users via the TEMIS (Tropospheric Emission Monitoring Internet Service) web site (http://www.temis.nl). The FRESCO cloud algorithm (version 5) was compared with 1 year of collocated ground-based radar/lidar cloud observations at the SGP/ARM (Southern Great Plains/Atmospheric Radiation Measurement) site (Wang et al., 2008). They reported that the FRESCO-retrieved cloud height was close to the midlevel of the clouds. The latest FRESCO algorithm (version 6, Wang et al., 2012) has been improved by using the MERIS surface albedo database (Popp et al., 2011) and the $\mathrm{O}_{2}$ line parameters from HITRAN (High Resolution Transmission) 2008 (Rothman et al., 2009). Cloud middle height is relevant for applications related to scattering in the shortwave spectral range, and for retrieval of cloud geometric thickness by combining cloud middle height with IR cloud top heights (Joiner et al., 2010, 2012).

The cloud top height in the SCIAMACHY ESA Level 2 (L2) operational product is derived from the $\mathrm{O}_{2} \mathrm{~A}$ band using SACURA (SemiAnalytical CloUd Retrieval Algorithm; Rozanov and Kokhanovsky, 2004; Kokhanovsky et al., 2006). For partly cloudy pixels, first the cloud fraction is retrieved using OCRA (Optical Cloud Recognition Algorithm; Loyola, 2004) and then the cloud top height is derived. OCRA retrieves cloud fraction using the broadband polarization measurement devices (PMDs). The pixel size of the PMDs is about one-eighth of the pixel size of the SCIAMACHY $\mathrm{O}_{2}$ A band measurements. However, the cloud top height cannot be derived from the PMD measurements. The SACURA algorithm implemented in the ESA L2 processor is a fast version of the scientific SACURA algorithm. Cloud top heights derived from GOME (Global Ozone Monitoring Experiment) and SCIAMACHY measurements using the SACURA algorithm have been compared with ground-based and satellite measurements for limited data sets and time 
periods (Kokhanovsky et al., 2006, 2007; Rozanov et al., 2006). Recently, Lelli et al. (2012) compared GOME cloud top heights retrieved using the SACURA algorithm with cloud top heights from radar/lidar measurements at ARM sites and Chilbolton. They found that the GOME cloud top height from SACURA was higher than the radar-measured cloud top for shallow clouds and lower than the radarmeasured cloud top for deep clouds. Here deep clouds refer to clouds of which the top is higher than $3 \mathrm{~km}$ and the vertical extent is greater than $50 \%$ of its height; other clouds are referred to as shallow clouds (Sayer et al., 2011).

The SCIAMACHY ESA L2 cloud product has been compared before with the FRESCO cloud product and the SACURA scientific product (Lichtenberg, 2009). The quality of a L2 product is not only determined by the retrieval algorithm but also by the quality of the Level 1 (L1) product used as input. The SCIAMACHY measurements have some degradation with time (Bramstedt, 2008), which may appear as a tendency in the cloud products if it is not corrected. The impact of the degradation could only be evaluated using a data set covering a long time period. In this paper the latest SCIAMACHY ESA L1 product (version 7.04-W, released in February 2012) is used for both cloud products, namely the ESA L2 product version 5.02 (released in June 2012) and the FRESCO product version 6 . This is the first time that the full time series of the latest SCIAMACHY ESA L2 cloud top height and FRESCO cloud height products are being validated with the same independent ground-based radar/lidar measurements.

In Sect. 2 we describe the validation data set. Section 3 contains the methodology for the validation. The results are presented in Sect. 4. Conclusions are drawn in Sect. 5.

\section{Data sets}

\subsection{SCIAMACHY FRESCO cloud product}

FRESCO has been developed as a simple, fast, and robust algorithm to provide cloud information for cloud correction in trace gas retrievals, such as ozone and $\mathrm{NO}_{2}$ (Koelemeijer et al., 2001; Wang et al., 2008). The effective cloud fraction (between 0 and 1) and the cloud pressure are retrieved simultaneously. The information on the effective cloud fraction comes from the continuum at about $758 \mathrm{~nm}$ whereas the depth of the $\mathrm{O}_{2} \mathrm{~A}$ band provides the information about the cloud pressure. The effective cloud fraction and the cloud pressure are independent. FRESCO uses the reflectances in three $1 \mathrm{~nm}$ wide windows of the $\mathrm{O}_{2}$ A band: $758-759 \mathrm{~nm}$, $760-761 \mathrm{~nm}$, and $765-766 \mathrm{~nm}$. In FRESCO the cloud is assumed to be a Lambertian reflector with albedo of 0.8. Only $\mathrm{O}_{2}$ absorption along the light path and single Rayleigh scattering are taken into account; absorption by oxygen inside the cloud is neglected. The transmission in the $\mathrm{O}_{2} \mathrm{~A}$ band is first calculated line-by-line based on the $\mathrm{O}_{2}$ line parameters in the HITRAN 2008 database (Rothman et al., 2009) and then convolved with the SCIAMACHY spectral response function (slit function). Surface albedo is an a priori parameter for FRESCO retrievals, and is taken from the MERIS monthly climatological surface albedo database (Popp et al., 2011). For a partly cloudy pixel, the reflectance is assumed to be the sum of the reflectances from the clear-sky part and the cloudy part of the pixel. The $\mathrm{O}_{2}$ transmission and Rayleigh scattering are calculated using the midlatitude summer (MLS) atmospheric profile (Anderson, 1986); therefore, cloud pressure can be converted into cloud height (and vice-versa) using the MLS atmospheric profile.

\subsection{SCIAMACHY ESA level 2 cloud product}

The SCIAMACHY ESA L2 cloud top height is derived using the SACURA algorithm. SACURA determines the cloud top height and cloud optical thickness (COT) using measurements of the cloud reflectance in the entire $\mathrm{O}_{2}$ A band at 756-770 nm (Rozanov and Kokhanovsky, 2004). The forward model simulates the reflectance at top of atmosphere (TOA), assuming clouds to be a single plane-parallel scattering layer and including multiple scattering and oxygen absorption above, below and inside the clouds, as well the surface reflection contribution. The cloud layer is characterized by a cloud top height and a geometric thickness. The phase function of the cloud layer is computed using Mie theory for an effective radius of $6 \mu \mathrm{m}$ according to Deirmendjian's cloud $\mathrm{C} 1$ model. The cloud phase function is assumed to be the same throughout the cloud layer. The SACURA algorithm is based on an analytic approximation of the reflectance for optically thick clouds (COT $\geq 5$ ), therefore the algorithm is much faster than an exact radiative transfer simulation. For broken clouds extra information on the cloud fraction is required, which can be obtained using OCRA, discussed below. The reflectance at TOA is assumed to be the sum of the reflectance from the cloud-free part of the pixel and the cloudy part of the pixel weighted by the cloud fraction. For the retrieval algorithm, in order to find the cloud top height $(h)$, the TOA reflectance is presented in the form of a Taylor expansion around the a priori assumed value of cloud top height $\left(h_{0}\right)$. The assumed cloud top height is $1 \mathrm{~km}$ in SACURA, which is a typical value for low clouds (Feigelson, 1981). Neglecting the nonlinear term, the cloud height is obtained from the fit to the measured reflectances in the $\mathrm{O}_{2}$ A band. The main assumption in SACURA is that the relationship between reflectance and cloud top height can be presented by a linear function on the interval $\left(h-h_{0}\right)$. The oxygen absorption cross sections are calculated from a correlated $k$ distribution method (Buchwitz et al., 2000). The SACURA algorithm was implemented in the SCIAMACHY ESA L2 processor at DLR (German Space Agency). The range of the ESA L2 cloud top height is $1-17 \mathrm{~km}$ and the COT range is from 5 to 101 . The ESA L2 cloud product is described in 
the SCIAMACHY L2 product's algorithm theoretical baseline document (Lichtenberg, 2011).

The ESA L2 operational cloud fraction is retrieved using OCRA, which is a PMD algorithm using the red, green and blue PMDs for cloud fraction determination (Loyola, 2004). The basic idea of OCRA is to decompose the radiance measured by an optical sensor into two components: the background and the clouds. The PMD radiances in the red (PMD3), green (PMD2) and blue (PMD1) are calculated and normalized by the sum of the three radiances. The cloud-free composite is created by selecting the pixels with minimum radiance out of the multitemporal data set. The fractional cloud cover, defined in the range $[0,1]$, is determined from the distance between the measured radiance and the cloudfree radiance. However, the cloud fraction also depends on scaling and offset factors that are proportional to the position of the white point $[1 / 3,1 / 3,1 / 3]$ in the RGB (red, green, blue) space.

\subsection{Cloudnet target classification product}

Cloudnet is a network of ground-based remote sensing sites for the continuous evaluation of cloud and aerosol profiles in operational numerical weather prediction models. Cloudnet started with three observation stations at Cabauw, Chilbolton, and Palaiseau around 2001. At present, besides the original sites, Cloudnet includes five new sites: Juelich (since 2010), Leipzig (since 2011), Lindenberg (since 2004), Mace Head (since 2008), and Potenza (since 2009). These sites provide vertical profiles of cloud cover and cloud ice and liquid water contents at high spatial and temporal resolution by using active sensors such as lidar and Doppler millimeter-wave radar. In order to retrieve cloud microphysical properties, the backscatter targets in each of the radar/lidar pixels have to be categorized into different classes (Illingworth et al., 2007).

The vertically pointing Doppler cloud radar and backscatter lidar are the most relevant instruments for the Cloudnet target classification (Hogan and O'Connor, 2004). The radar can detect rain, drizzle drops, ice particles, and insects, because it is sensitive to large particles. Cloud droplets and aerosols can be identified from lidar measurements, because the lidar is sensitive to small particles (Illingworth et al., 2007). In the target classification product, each radar/lidar backscatter pixel is classified as liquid droplets, ice, insects, aerosols, clear-sky, or other categories. The target classification product also contains cloud top height and cloud base height. Cloud top and cloud base heights correspond to the highest and lowest of backscatter altitude grid boxes, respectively, that have clouds. Therefore, for multilayer clouds, the cloud top height refers to the top of the highest layer of the clouds and the cloud base height refers to the base of the lowest cloud layer. An example of the Cloudnet target classification product at Lindenberg (Germany) is shown in Fig. 1. At Cabauw (the Netherlands) the target classification product is produced every $15 \mathrm{~s}$ at $90 \mathrm{~m}$ vertical resolution. At
Lindenberg, the cloud profile has a time resolution of $30 \mathrm{~s}$ and a vertical resolution of $30 \mathrm{~m}$. A summary of the Cloudnet target classification product at Cabauw and Lindenberg is given in Table 1.

\subsection{Simulated FRESCO retrievals for SCIAMACHY}

In order to understand the validation results shown later on, $\mathrm{O}_{2} \mathrm{~A}$ band spectra of several cloud cases are simulated using the Doubling-Adding KNMI (Royal Netherlands Meteorological Institute) code (DAK) and retrievals are performed using the FRESCO algorithm. DAK is a plane-parallel radiative transfer model with pseudo-spherical correction at large solar zenith angles (De Haan et al., 1987; Stammes, 2001). It includes multiple scattering and polarization. The clouds can be specified at any layer of the atmosphere and different scattering phase matrices for clouds can be used. The gas absorptions are calculated line-by-line using the parameters from the HITRAN 2008 database (Rothman et al., 2009). In the simulations, the clouds are at 5 different heights: (a) cloud top at $2 \mathrm{~km}$ and cloud base at $1 \mathrm{~km}$, (b) cloud top at $6 \mathrm{~km}$ and cloud base at $5 \mathrm{~km}$, (c) cloud top at $10 \mathrm{~km}$ and cloud base at $9 \mathrm{~km}$, (d) cloud top at $6 \mathrm{~km}$ and cloud base at $2 \mathrm{~km}$, and (e) cloud top at $10 \mathrm{~km}$ and cloud base at $3 \mathrm{~km}$, respectively, to represent low, middle, high clouds, thick middle clouds, and thick high clouds. The COT values are 5, 15, and 35 for cloud cases a-c and 15, 35, and 60 for cloud cases $d$ and e. The scattering phase matrix for water clouds is calculated using Mie theory. The cloud droplets have a two-parameter gamma size distribution with an effective radius of $6 \mu \mathrm{m}$ and an effective variance of $0.15 \mu \mathrm{m}$. Surface albedos $\left(A_{\mathrm{s}}\right)$ of 0.05 and 0.3 are used to represent the albedo of ocean surface (dark surface) and grass-covered surface (bright surface) at $758 \mathrm{~nm}$, respectively. The $\mathrm{O}_{2}$ A band spectra are simulated at $0.01 \mathrm{~nm}$ resolution and convolved with the spectral response function of SCIAMACHY (full width at half maximum about $0.45 \mathrm{~nm}$ ). Ten solar zenith angles and 10 viewing zenith angles between 0 and $85^{\circ}$ are used in the simulations. We use the midlatitude summer atmospheric profile (Anderson, 1986) and the surface height is assumed to be $0 \mathrm{~km}$. The geometric cloud fraction is 1. Simulations have been performed before to understand the FRESCO retrievals (Wang et al., 2008; Sneep et al., 2008), but those simulations were only representative for clouds over a dark surface. Because the Cabauw and Lindenberg Cloudnet sites are both covered with vegetation, the new simulations should provide a better physical explanation of the validation results.

The cloud heights retrieved from the FRESCO algorithm are shown in Fig. 2 for a solar zenith angle of $60^{\circ}$ in the nadir viewing direction. The FRESCO-retrieved cloud heights are close to the cloud middle for the simulations over a dark surface. For the simulations over a bright surface, the retrieved cloud height can be higher than the cloud top height for optically thin clouds, say COT $\leq 5$. At large SZA and small COT, the retrieved cloud heights are often at $15 \mathrm{~km}$. Over a 
Table 1. Information on the Cloudnet target classification product at Cabauw and Lindenberg.

\begin{tabular}{llllllll}
\hline & $\begin{array}{l}\text { Latitude } \\
\left({ }^{\circ} \mathrm{N}\right)\end{array}$ & $\begin{array}{l}\text { Longitude } \\
\left({ }^{\circ} \mathrm{E}\right)\end{array}$ & $\begin{array}{l}\text { Surface } \\
\text { height }(\mathrm{m})\end{array}$ & $\begin{array}{l}\text { Time } \\
\text { resolution }(\mathrm{s})\end{array}$ & $\begin{array}{l}\text { Altitude } \\
\text { range }(\mathrm{m})\end{array}$ & $\begin{array}{l}\text { Altitude } \\
\text { grid }(\mathrm{m})\end{array}$ & $\begin{array}{l}\text { Time } \\
\text { period }\end{array}$ \\
\hline Cabauw & 51.97 & 4.93 & -0.7 & 15 & $253-11500$ & 90 & Jan 2003-Jun 2005 \\
Lindenberg & 52.21 & 14.13 & 103.0 & 30 & $324-15000$ & 30 & Jan 2005-Dec 2011 \\
\hline
\end{tabular}
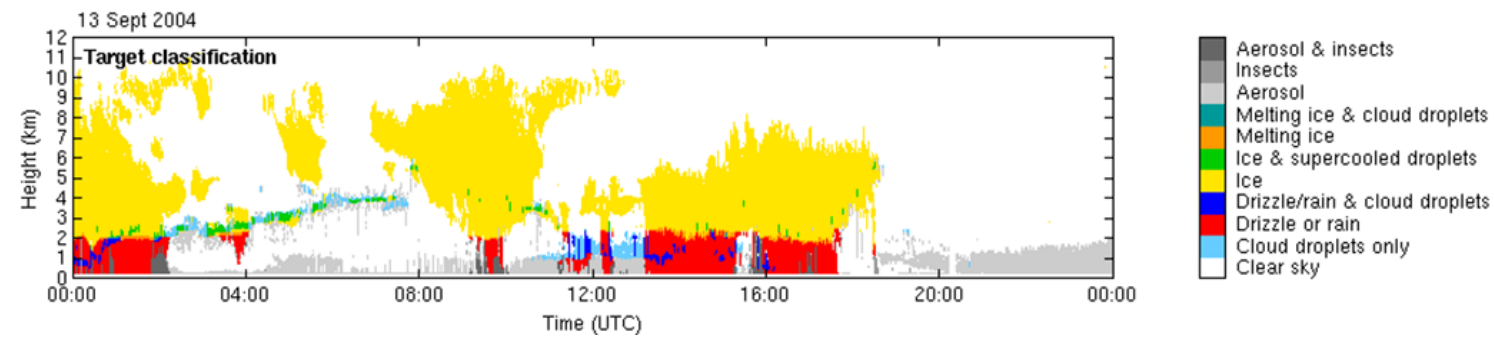

Figure 1. Quick-look image of the Cloudnet target classification product at Lindenberg on 13 September 2004 (downloaded from www. cloud-net.org).

bright surface, the light path between the surface and clouds becomes important, while this long light path is missing in the FRESCO cloud model. The retrieval tries to simulate this long light path by reducing the cloud fraction and putting the cloud at a high altitude. In this case, the FRESCO retrievals have larger errors. For optically thick clouds, at COT $\geq 35$, the surface albedo has almost no impact on the reflectance at the top of the atmosphere. Consequently, FRESCO-retrieved cloud heights are very similar for the dark and bright surfaces. The chi-square values are larger for the $A_{\mathrm{s}}=0.3$ cases than for the $A_{\mathrm{s}}=0.05$ cases, which suggests that the fit is better over a dark surface.

\section{Methodology}

The FRESCO and ESA L2 cloud products are processed using the same SCIAMACHY L1 data. The SCIAMACHY FRESCO and ESA L2 global cloud products are first intercompared to show the general features of the $\mathrm{O}_{2} \mathrm{~A}$ band cloud retrievals and to give more statistics. Next, the validation is performed using collocated SCIAMACHY data and Cloudnet radar/lidar measurements.

The Cloudnet target classification product and cloud boundaries at Cabauw and Lindenberg are used for the validation of SCIAMACHY cloud height products, because they have long continuous data sets: from January 2001 to June 2005 at Cabauw and from January 2005 until now at Lindenberg. For the validation the Cloudnet and SCIAMACHY measurements from January 2003 to December 2011 are used to construct a collocated data set.

For every SCIAMACHY pixel covering Cabauw or Lindenberg, $1 \mathrm{~h}$ of Cloudnet target classification data, centered at the SCIAMACHY overpass time $( \pm 30 \mathrm{~min})$, is selected as collocated data. Thus, for every cloud height measurement from SCIAMACHY there are about 240 (temporal) $\times 126$ (vertical) radar/lidar backscatter pixels at Cabauw and 120 (temporal) $\times 450$ (vertical) radar/lidar backscatter pixels at Lindenberg, which are classified as one of the 10 categories or clear-sky. The categories "ice" and "cloud droplets only" are used to determine ice and water clouds (see Fig. 1). The categories with "drizzle" and "rain" usually occur at the cloud base, so they have no impact on the SCIAMACHY cloud retrievals. The cloud radars at Cabauw and Lindenberg are operated at $35 \mathrm{GHz}$. Only in heavy rain can the sensitivity of the cloud radars to high clouds be affected (Illingworth et al., 2007). Therefore, the cases with precipitation are included in the validation data set. The radars can miss some high clouds with optical thickness of less than 0.1 . This has no impact on the intercomparison because these thin clouds cannot be observed properly by SCIAMACHY.

Height distributions of the radar/lidar backscatter pixels are derived for ice clouds, water clouds, and both types, respectively, from 250 to $12000 \mathrm{~m}$ with a bin size of $270 \mathrm{~m}$. Some examples of cloud height distributions are shown in Fig. 3. If the distribution has a single mode without interruption by clear-sky pixels, the cloud case is classified as a single-layer cloud. If more than one mode appears in the distribution and these modes are separated by clear-sky pixels, the case is classified as a multilayer cloud. As illustrated in Fig. 3, single-layer cloud A has a single peak, whereas single-layer cloud B has two local peaks; but since there are no clear-sky pixels between the two peaks, case B is classified as a single-layer cloud.

The validation is performed separately for single-layer clouds and multilayer clouds, because in the SACURA and FRESCO cloud retrieval algorithm clouds are assumed to be single layers. Water and ice clouds have different scattering matrices, therefore the single-layer clouds are further 


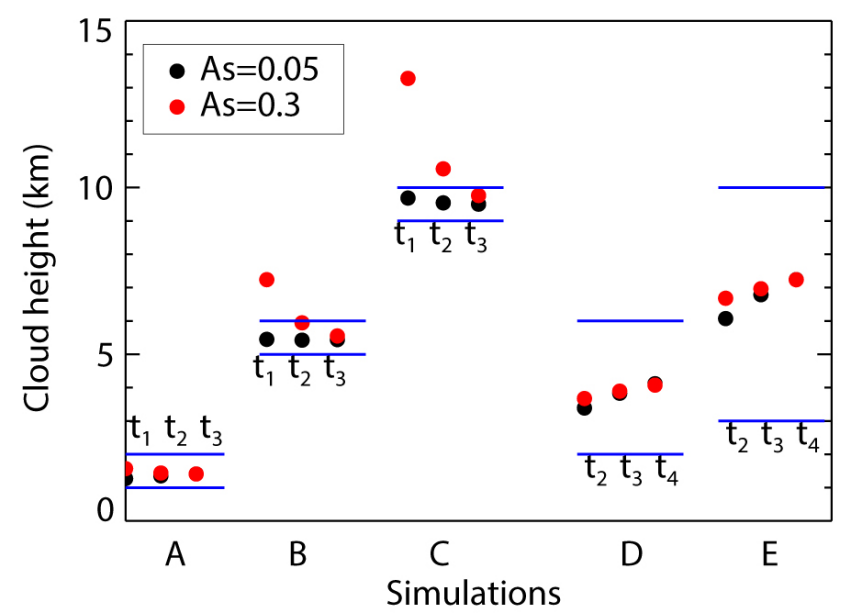

Figure 2. FRESCO-retrieved cloud heights for simulated cloud cases for a solar zenith angle of $60^{\circ}$ and nadir view. The cloud optical thickness values are $\tau_{1}=5, \tau_{2}=15, \tau_{3}=35, \tau_{4}=60$. Cloud top and base heights are indicated using blue horizontal lines. The surface albedos $\left(A_{\mathrm{S}}\right)$ are 0.3 and 0.05 .

separated into water and ice clouds. The Cloudnet cloud top height is the arithmetic mean of the cloud top heights in a $1 \mathrm{~h}$ period around the SCIAMACHY overpass time; the same holds for the cloud base height. We define a "cloud middle height", which is the arithmetic mean of the heights of the targets which are classified as "ice" and/or "cloud droplets only". The cloud middle height depends on the cloud height distribution; it often differs from the mean of cloud top and cloud base heights.

In the validation of FRESCO and ESA L2 cloud heights using the Cloudnet data, we are mainly focusing on the scenes having effective cloud fractions larger than 0.1 . This criterion is necessary because the ESA L2 cloud top heights are often not retrieved for scenes having an effective cloud fraction smaller than 0.1. The ESA L2 cloud product provides flags in bits for the quality of the SACURA retrievals, which can be interpreted in the following categories: (1) full convergence, (2) number of iterations exceeded, (3) cloud layer size set to constraint, (4) cloud bottom height set to constraint, (5) cloud top height set to constraint, and (6) no convergence. If the algorithm does not converge, the cloud top height is a filled value (-99.9). If the ESA L2 cloud fraction is 0 , cloud top height is also 0 . For the retrievals having flags of 1-5, the cloud top heights are provided in a range of $1-17 \mathrm{~km}$. The full convergence retrievals have an error of $0.25 \mathrm{~km}$ for cloud top height, while the retrievals with constraints have an error of $0.5 \mathrm{~km}$ (Meringer, 2010). Because we would like to evaluate the quality of the complete cloud top height product, we use all the ESA L2 cloud top heights between 1 and $17 \mathrm{~km}$ which means the data having flags $1-5$ are used.

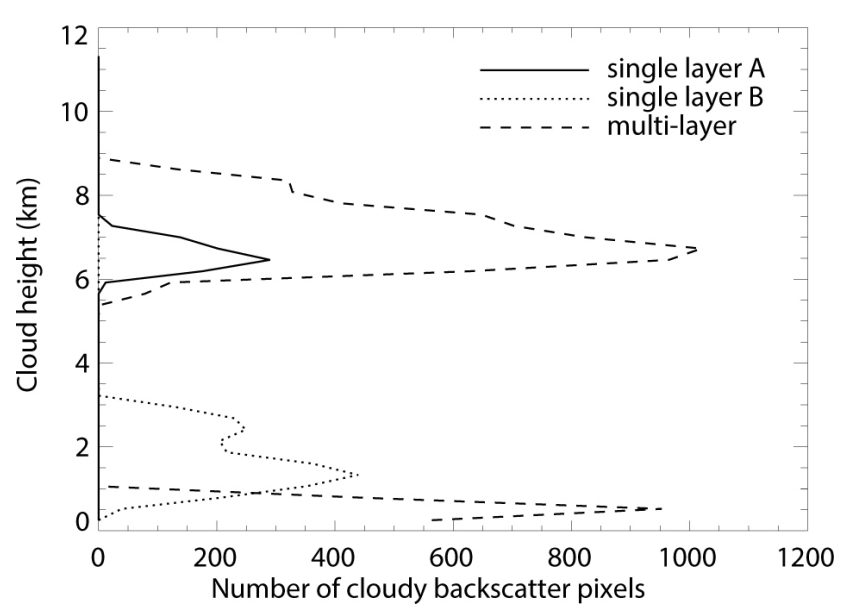

Figure 3. Three examples of Cloudnet cloud vertical distributions: two single-layer cases and one multilayer case. The distributions are based on $1 \mathrm{~h}$ of data centered at the SCIAMACHY overpass time (about 10:00 LT).

\section{Results}

\subsection{Global intercomparison of FRESCO and ESA L2 cloud products}

In order to present a global view of the SCIAMACHY FRESCO and ESA L2 cloud products and to examine the degradation correction of the SCIAMACHY L1 data, the FRESCO and ESA L2 cloud products are compared using a data set consisting of one orbit per month from the entire SCIAMACHY mission period and 4 full days of global data. The selected data set covers the whole globe and a long time period. Although the ESA L2 cloud fraction is derived from the PMDs, the cloud fraction in the L2 cloud product is provided for the same pixel as the cloud top height, which is derived from the spectrometer's $\mathrm{O}_{2}$ A band channel. The collocation of SCIAMACHY FRESCO and ESA L2 cloud products is determined from the measurement time. The collocated data are only for SCIAMACHY pixels without snow/ice on the surface. The snow/ice pixels are determined in FRESCO using the TOMS surface albedo climatology. FRESCO only retrieves effective cloud fraction and cloud pressure (cloud height) for non-snow/ice pixels. For snow/ice pixels, FRESCO assumes a cloud fraction of 1 and retrieves the scene albedo and the scene pressure. The data set has in total about $9 \times 10^{5}$ collocated data points for (effective) cloud fraction and $6 \times 10^{5}$ for cloud (top) height. Because of non-convergence in the SACURA retrievals, the amount of collocated cloud (top) height data is less than the amount of cloud fraction data. The mean SZA in this data set is $60.0^{\circ}$ with a standard deviation of $19.4^{\circ}$. The FRESCO and ESA L2 (effective) cloud fraction and cloud (top) height show no visible tendency with time. It suggests that after the instrumental degradation correction, the degradation of the 

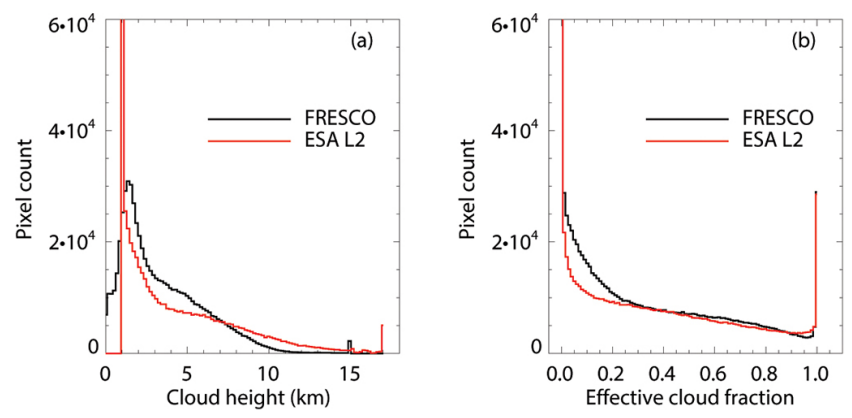

Figure 4. (a) Histogram of SCIAMACHY FRESCO cloud height and ESA L2 cloud top height for global data. (b) Histogram of SCIAMACHY FRESCO effective cloud fraction and ESA L2 cloud fraction. The pixel count for the ESA L2 product (out of range in the plots) is $1.6 \times 10^{5}$ at cloud height of $1 \mathrm{~km}$ in (a) and is $2.0 \times 10^{5}$ at effective cloud fraction of 0.0 in (b).

SCIAMACHY L1 measurements has no obvious effect on neither the cloud fraction nor the cloud (top) height retrieved by the investigated algorithms. The global statistics of the FRESCO and ESA L2 cloud products are summarized in Table 2 .

The global frequency distributions of the FRESCO cloud height and ESA L2 cloud top height are shown in Fig. 4a. Both histograms have a maximum at $1-2 \mathrm{~km}$, which indicates the global dominance of low clouds. The ESA L2 cloud top height distribution is cut off at $1 \mathrm{~km}$ as the lowest value, which is a feature of the SACURA algorithm. The FRESCO mean cloud height is $0.6 \mathrm{~km}$ lower than the ESA L2 mean cloud top height. The difference between ESA L2 and FRESCO cloud heights decreases with increasing ESA L2 COT because both FRESCO and ESA L2 cloud algorithms are most suitable for optically thick clouds (see Sect. 2). The difference between ESA L2 and FRESCO cloud heights does not depend on the effective cloud fraction, the solar zenith angle or the ESA L2 convergence flags. These differences can be understood from the principles of the FRESCO and SACURA algorithms. Both algorithms retrieve the cloud height from the amount of $\mathrm{O}_{2}$ absorption at $760 \mathrm{~nm}$, which determines the length of the light path above the cloud and inside the cloud. Multiple scattering inside the cloud is taken into account in the SACURA algorithm but not in the FRESCO algorithm. In FRESCO the light path of photons inside the cloud is added to the light path above the cloud. Therefore, FRESCO retrieves a lower cloud height than SACURA. As shown in Fig. 2, FRESCO effectively retrieves a cloud midlevel height, especially over dark surfaces. The FRESCO-retrieved cloud height increases with increasing COT for geometrically thick clouds. This may explain the COT dependence of the difference between the ESA L2 and FRESCO cloud heights. In reality, the retrieved cloud heights could be different from the simulations due to different cloud optical properties and different solar and viewing geometries.
The FRESCO effective cloud fraction and the ESA L2 cloud fraction, shown in Fig. 4b, have similar distributions except at effective cloud fractions of less than 0.2. In that range the ESA L2 cloud fraction product is sharper peaked (more cloud-free pixels), whereas the FRESCO effective cloud fraction product has a wider distribution. Because the cloud fraction in the ESA L2 product is derived from PMDs, which have a pixel size of about $7 \mathrm{~km} \times 30 \mathrm{~km}$, it has slightly more clear-sky pixels than FRESCO (Krijger et al., 2007). This may cause differences between ESA L2 cloud fraction and FRESCO effective cloud fraction at small cloud fractions. However, the ESA L2 cloud fraction and FRESCO effective cloud fraction are very similar: the global mean difference (ESA L2 - FRESCO) is only $-0.023(6 \%)$ with a standard deviation of 0.1 . The consistence between the ESA L2 cloud fraction and FRESCO effective cloud fraction suggests that the ESA L2 cloud fraction is actually an effective cloud fraction for optically thick clouds (with cloud albedo of 0.8 ). The relationship between geometric cloud fraction and effective cloud fraction has been described by Stammes et al. (2008).

\subsection{Validation}

From January 2003 to December 2011, there are 693 collocated SCIAMACHY and Cloudnet measurements, of which 157 cases are excluded because of almost cloud-free conditions (Cloudnet cloud fraction $<0.05$ ). In the remaining 536 cases, 297 cases are single-layer clouds and 239 cases are multilayer clouds. The single-layer cloud cases with FRESCO effective cloud fraction $>0.1$ (217 cases) include 71 cases of water clouds (class "cloud droplets only"), 103 cases of ice clouds (class "ice"), and 43 cases having coexisting water and ice clouds. For the multilayer clouds, ice and water clouds are not analyzed separately, because most multilayer clouds have both ice and water cloud droplets. The number of cloud-free cases is 99 according to the Cloudnet products. According to the ESA L2 product there are 82 cloud-free cases. This difference can occur due to errors in the satellite cloud detection technique, and due to partial collocation, e.g., if the Cloudnet site is located at the edge of the SCIAMACHY pixel. For the cloud-free pixels in the ESA L2 cloud product, the mean of the FRESCO effective cloud fractions is 0.0244 . This is in good agreement with the global difference of 0.0225 between the FRESCO and ESA L2 cloud fractions (see Table 2).

\subsubsection{Single-layer clouds}

Figure 5 shows the scatter plots of the FRESCO cloud height vs. the Cloudnet cloud top height for all collocated single-layer clouds, single-layer water clouds and singlelayer ice clouds. The color scale indicates the FRESCO effective cloud fraction. The sum of ice cloud cases and water cloud cases is smaller than the total number of cases, 
Table 2. Statistics of SCIAMACHY FRESCO (v6) and ESA L2 (v5.02) global cloud products, $\sigma$ - standard deviation.

\begin{tabular}{|c|c|c|c|c|c|c|c|}
\hline & \multicolumn{3}{|c|}{ Effective cloud fraction } & \multicolumn{3}{|c|}{ Cloud (top) height (km) } & \multirow[b]{2}{*}{$\begin{array}{l}\text { time } \\
\text { period }\end{array}$} \\
\hline & mean & $\sigma$ & $\begin{array}{r}\text { no. of } \\
\text { data }\end{array}$ & mean & $\sigma$ & $\begin{array}{r}\text { no. of } \\
\text { data }\end{array}$ & \\
\hline FRESCO (v6) & 0.348 & 0.302 & 924335 & 3.53 & 2.54 & 630404 & August 2002- \\
\hline ESA L2 (v5.02) & 0.326 & 0.314 & 924335 & 4.14 & 3.53 & 630404 & April 2012 \\
\hline FRESCO-ESA & 0.0225 & 0.100 & 924335 & -0.609 & 2.16 & 630404 & \\
\hline
\end{tabular}
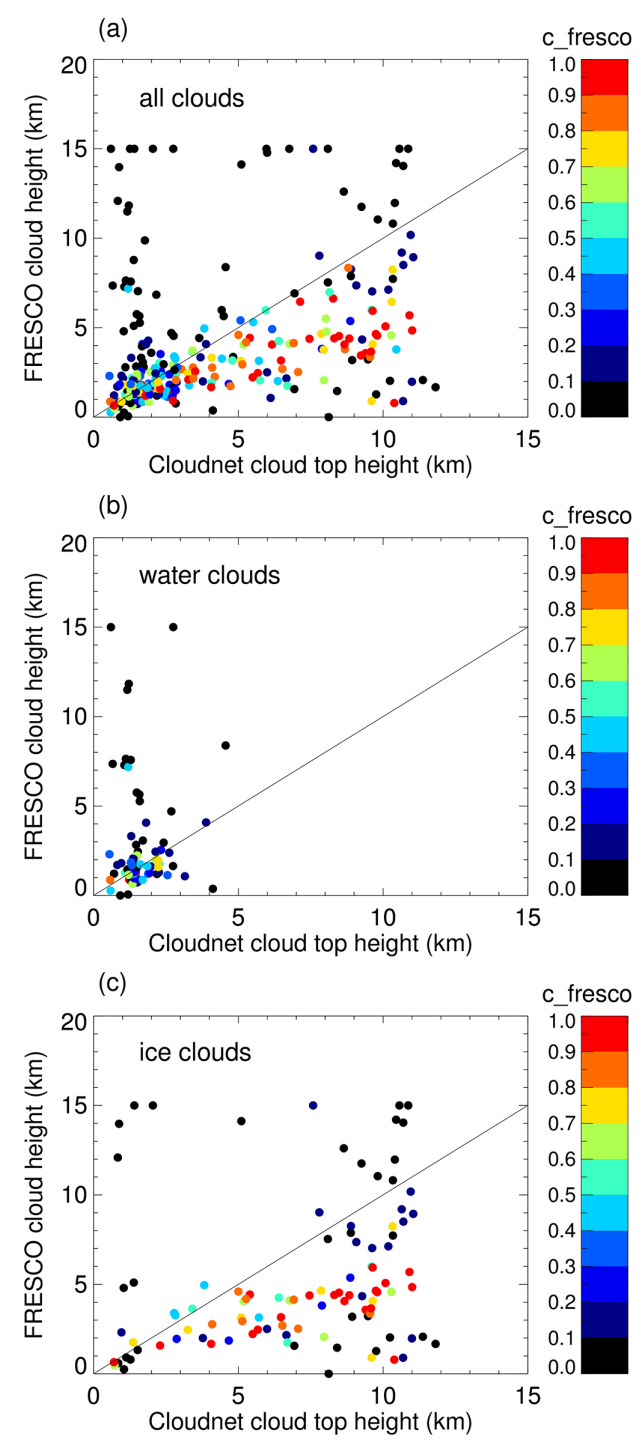

Figure 5. Scatter plots of SCIAMACHY FRESCO cloud height vs. Cloudnet cloud top height, for (a) all single-layer clouds, (b) singlelayer water clouds, and (c) single-layer ice clouds. The color of the symbol indicates the FRESCO effective cloud fraction, with the color code given by the vertical bar. The black line is the one-to-one line. For the points with c_fresco $>0.1$, the correlation coefficients are (a) 0.685 , (b) 0.206, and (c) 0.489 . because some single-layer clouds have both ice and water droplets. If the FRESCO effective cloud fraction is less than 0.1 , the FRESCO cloud heights show large scatter. FRESCO cloud heights are in good agreement with Cloudnet cloud top heights for low clouds, but are lower than the Cloudnet cloud top heights for high clouds. This behavior does not depend on the effective cloud fraction. The linear correlation coefficients and $p$ values are calculated for the data in Fig. 5 for the cases having effective cloud fraction $>0.1$. The correlation coefficients are tested for their significance and expressed as a $p$ value. A small $p$ value suggests that the correlation is significant. Results having a $p$ value $<0.01$ are defined significant in this paper. The criteria on effective cloud fraction and $p$ value are also applicable to all correlation analyses in Sect. 4. The correlation coefficients between the FRESCO cloud height and the Cloudnet cloud top height are $0.685,0.206$, and 0.489 for all, water, and ice (singlelayer) clouds, respectively. The corresponding $p$ values for all, water, and ice clouds are $0.0,0.170$, and $1.75 \times 10^{-5}$. According to the above defined $p$ value threshold, the linear correlation between the FRESCO cloud height and the Cloudnet cloud top height is significant for all clouds and ice clouds, but not for water clouds. The small correlation coefficient for water cloud cases is mainly caused by a few outliers. The small effective cloud fraction values indicate that these water clouds are optically thin, which is not a favorable condition for the FRESCO algorithm. The correlation coefficient between the FRESCO cloud height and Cloudnet cloud top height is much larger for the cases having large effective cloud fractions.

The ESA L2 cloud top height is plotted vs. the Cloudnet cloud top height for all collocated single-layer clouds in Fig. 6. The color scale indicates the ESA L2 cloud fraction (derived from OCRA). Cloud top heights of water clouds are usually below $4 \mathrm{~km}$ in these Cloudnet measurements. The ESA L2 cloud top height tends to be higher than the water cloud top height; however, the agreement seems to be better for low ice clouds. There is no ESA L2 cloud top height retrieval for effective cloud fractions of less than 0.1 . In some cases the ESA L2 cloud algorithm does not converge; therefore its cloud top height product has less data than the FRESCO cloud height product. Figure 6 a shows that the L2 cloud top height tends to be higher than the Cloudnet cloud top height for small cloud fractions and lower than 


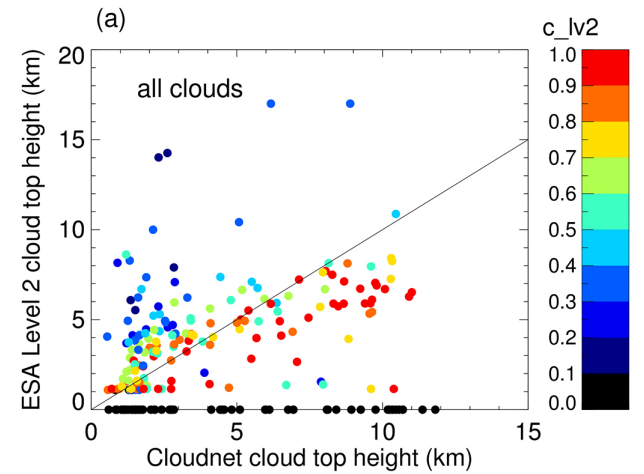

(b)

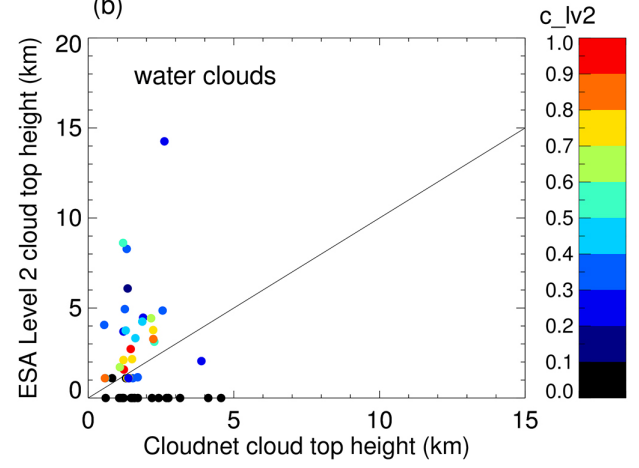

(c)

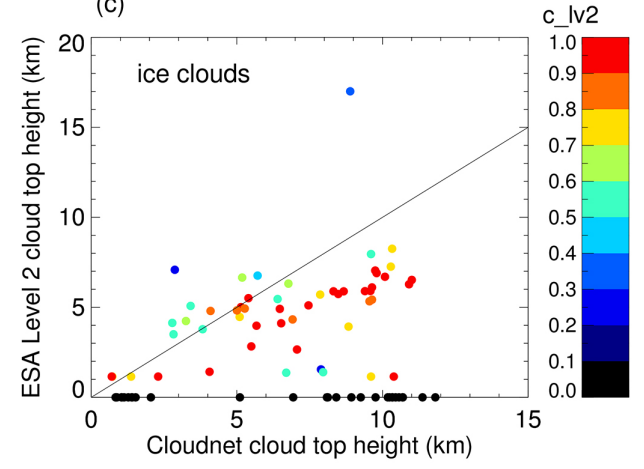

Figure 6. Scatter plots of SCIAMACHY ESA L2 cloud top height versus Cloudnet cloud top height for (a) all single-layer clouds, (b) single-layer water clouds, and (c) single-layer ice clouds. The color of the symbol indicates the ESA L2 cloud fraction, with the color code given by the vertical bar. The black line is the one-to-one line. For the points with c_lv $2>0.1$, the correlation coefficients are (a) 0.451, (b) 0.247, and (c) 0.426 .

the Cloudnet cloud top height for large cloud fractions. In a cloudy scene, the effective cloud fraction is proportional to the cloud albedo, which increases with increasing cloud optical thickness (Stammes et al., 2008). Figure 6 indicates that the difference between the ESA L2 cloud top height and the Cloudnet cloud top height may be related to cloud optical thickness. The correlation coefficients between the ESA L2 cloud top height and the Cloudnet cloud top height are $0.451,0.247$, and 0.426 with $p$ values of $4.24 \times 10^{-10}, 0.188$, and $1.66 \times 10^{-3}$ for all clouds, water clouds and ice clouds,

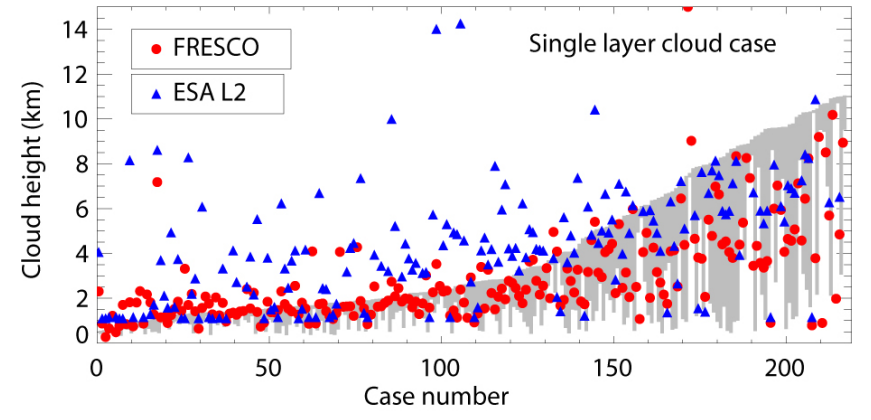

Figure 7. Comparison between SCIAMACHY ESA L2 cloud top height, FRESCO cloud height, and Cloudnet cloud top and cloud base height for single-layer clouds. The cases are sorted according to the Cloudnet cloud top height. The grey bar indicates the altitude range of the cloud according to the Cloudnet product. Here the cases with FRESCO effective cloud fraction below 0.1 are excluded.

respectively. Therefore, the correlation coefficients are significant for all clouds and ice clouds. In Fig. 6b, the small correlation coefficient for water cloud cases is caused by some outliers and by the cases where the ESA L2 cloud top heights are set to constraint at $1.1 \mathrm{~km}$. As shown in Fig. $6 \mathrm{~b}$ the ESA L2 cloud top height and the Cloudnet cloud top height have a good linear correlation for water clouds having c_lv2 $>0.7$.

Figure 7 shows the single-layer cloud cases sorted according to the Cloudnet cloud top height. The grey bar marks the Cloudnet cloud vertical range from cloud base height to cloud top height. The red and blue points indicate the FRESCO cloud height and ESA L2 cloud top height, respectively. These are the same single-layer cloud cases as in Figs. 5 and 6, but excluding the cases that have a FRESCO effective cloud fraction of less than 0.1. For the cases in Fig. 7, the mean and median of the geometric cloud fraction derived from the Cloudnet measurements are, respectively, 0.84 and 0.99 . Therefore, most of the cases are fully cloudy for $1 \mathrm{~h}$ of collocated Cloudnet measurements. The mean variations of Cloudnet cloud top and cloud base heights within an hour are both about $340 \mathrm{~m}$ and the medians about $220 \mathrm{~m}$.

As shown in Fig. 7, the ESA L2 cloud top height is higher than the FRESCO cloud height, which agrees with the global intercomparison of ESA L2 cloud top height and FRESCO cloud height (see Sect. 4.1). The FRESCO cloud height and ESA L2 cloud top height are mainly below the Cloudnet cloud top height and above the cloud base height. It is well understood that since light can penetrate into the clouds, the retrieved cloud height from the $\mathrm{O}_{2} \mathrm{~A}$ band is often lower than the cloud top height (Ferlay et al., 2010; Desmons et al., 2013; Sneep et al., 2008; Wang et al., 2008). The simulations shown in Fig. 2 illustrate that the FRESCO-retrieved cloud height is mainly between the cloud top and cloud base heights. For high thin clouds, many photons are transmitted and reach the surface before being reflected back to space. This light path is not included in FRESCO. Furthermore, the 
amount of $\mathrm{O}_{2}$ absorption in scenes with thin cirrus can be very close to that of cloud-free scenes. Therefore, any small errors in the simulated $\mathrm{O}_{2}$ absorption would cause the retrieval not to converge or yield a cloud height close to the surface or the upper limit of $15 \mathrm{~km}$.

For the low clouds in Fig. 7, the FRESCO cloud height and ESA L2 cloud top height are often higher than the Cloudnet cloud top height. Furthermore, the ESA L2 cloud top height is very noisy. We have further analyzed these low cloud cases (Cloudnet cloud top height $<2 \mathrm{~km}$ ). In Fig. 7 the cloud cases $0-81$ are used in the following analysis. The SZA in these 82 cases is in the range of $31-78^{\circ}$ with a mean SZA of $55^{\circ}$. The ESA L2 COT values are from 5 to 101 and include some filled values $(-99.9)$, which is due to low reflectance $(\mathrm{COT}<5)$. Although the ESA L2 COT may have a bias or a large error in some cases, the COT for the single-layer clouds are more reliable than for the multilayer clouds (Rozanov and Kokhanovsky, 2004) and are retrieved consistently. For the simulated cloudy cases shown in Fig. 2, the effective cloud fractions over a dark (bright) surface are $0.3(0.2)$ for COT of 5. This suggests that the cases having ESA L2 COT of -99.9 may have COT $<5$ and an effective cloud fraction $>0.1$.

For the cases where FRESCO cloud heights are higher than the Cloudnet cloud top heights, the median of the ESA L2 COT is 9 with some filled values; the mean and median of the SZA are $63^{\circ}$ and $68^{\circ}$, respectively. From the simulations in Sect. 2.4 we find that the FRESCO-retrieved cloud height can be above the cloud top over a bright surface if COT is smaller than 15 and for large $\operatorname{SZA}\left(>60^{\circ}\right)$. For the low cloud cases with COT $=5$ and $A_{\mathrm{s}}=0.3$, the FRESCO-retrieved cloud height is higher than the cloud top at $\mathrm{SZA}=70^{\circ}$. If COT is $<5$, the simulated FRESCO cloud height would be above the cloud top height at slightly smaller SZA. In the 82 cases, the difference between the FRESCO cloud height and the Cloudnet cloud top height tends to increase with increasing SZA with a slope of about $0.03 \mathrm{~km}_{\text {degree }}{ }^{-1}$. Based on the simulations of Sect. 2.4 we may conclude that for low clouds, the fact that the FRESCO cloud height is higher than the Cloudnet cloud top height, is caused by the bright surface $\left(A_{\mathrm{S}}=0.3\right)$, small COT, and large SZA.

The difference between the ESA L2 and the Cloudnet cloud top height is larger at small COT and smaller at large COT for these 82 low cloud cases. For $5 \leq \mathrm{COT}<15$, $15 \leq \mathrm{COT}<35$, and COT $\geq 35$, the mean (median) of the cloud top height differences (ESA L2 - Cloudnet) are 2.9 (2.5), $0.9(0.4)$, and $0.1(0.2) \mathrm{km}$, respectively. For the ESA L2 data, the reason for the positive bias could be attributed to small COT, while it has no correlation with SZA. Because the approximation used in SACURA is more accurate for optically thick clouds, it is not a surprise that the retrievals are more accurate at large COT. The bright surface and the cloud phase function might contribute to the bias. Although most low clouds are water clouds, there are mixed-phase clouds. Retrieval errors in SACURA related to a bright surface may need more investigation.
Because the Cloudnet cloud top height covers a range of $0.25-12 \mathrm{~km}$, it would be too coarse to give only a mean difference. SCIAMACHY cloud heights and Cloudnet cloud heights for single-layer clouds have been analyzed for vertical bins. The Cloudnet cloud top heights are divided into $1 \mathrm{~km}$ bins from 0 to $8 \mathrm{~km}$, a bin for $8-10 \mathrm{~km}$ and a bin above $10 \mathrm{~km}$. For every Cloudnet cloud top height bin, the corresponding FRESCO cloud heights and ESA L2 cloud top heights are selected and the mean and standard deviations are calculated. The results are presented in bar plots in Fig. 8. The number of cases in each bin is the same for the Cloudnet data and FRESCO data, while the number of cases for ESA L2 data is generally less because of non-convergence or no retrievals. Therefore, the number of Cloudnet cloud data in every bin used to compare with ESA L2 cloud top height is less than that used to compare with FRESCO cloud height. For the clarity of the figures, in Figs. 8 and 12, only the Cloudnet cloud heights for collocated FRESCO cloud heights are shown. The Cloudnet cloud heights for collocated ESA L2 cloud top heights are provided in the tables in the Appendix. As shown in Fig. 8a, below $4 \mathrm{~km}$ the FRESCO cloud height is close to the Cloudnet cloud top height; the differences are between $0.20 \mathrm{~km}$ (bin 2) and $-0.57 \mathrm{~km}$ (bin 4), which include $62 \%$ of 217 cases. The ESA L2 cloud top height is close to the Cloudnet cloud top height for the bins at $4-7 \mathrm{~km}$; the differences are between $-0.04 \mathrm{~km}$ (bin 5) and $0.72 \mathrm{~km}$ (bin 4), which include $24 \%$ of 174 cases. However, the mean difference between ESA L2 and Cloudnet cloud top heights is small: the ESA L2 cloud top height is only $0.44 \mathrm{~km}$ higher than the Cloudnet cloud top height, with a standard deviation of $3.07 \mathrm{~km}$. FRESCO cloud height is about $1.25 \mathrm{~km}$ lower than the Cloudnet cloud top height, with a standard deviation of $2.31 \mathrm{~km}$.

Figure $8 \mathrm{~b}$ shows the comparisons for $1 \mathrm{~km}$ bins of the Cloudnet cloud middle height and the SCIAMACHY cloud height products. The number of data in each bin is different from Fig. 8a, because a Cloudnet cloud can fall into a different bin by considering the cloud top height or the cloud middle height. For example, in bin 10 the number of Cloudnet cloud top heights is 15 but the number of Cloudnet cloud middle heights is 6 . The FRESCO cloud height has a good agreement with the Cloudnet cloud middle height for $85 \%$ of the cases and for the bins from 0 to $6 \mathrm{~km}$. The smallest difference of $0.01 \mathrm{~km}$ occurs in the $2-3 \mathrm{~km}$ bin. The mean difference between the FRESCO cloud height and the Cloudnet cloud middle height is only $-0.14 \mathrm{~km}$, with a standard deviation of $1.88 \mathrm{~km}$. The values that are used in Fig. 8 are provided in Tables A1-A4 in the Appendix.

In reality cloud top heights can occur in a large range from the surface up to $15-20 \mathrm{~km}$. The FRESCO cloud height and ESA L2 cloud top height have a different accuracy for clouds having different cloud top heights, optical thicknesses and probably other properties. The mean and standard deviations of the difference between the SCIAMACHY cloud heights and the Cloudnet cloud top height actually give the error 

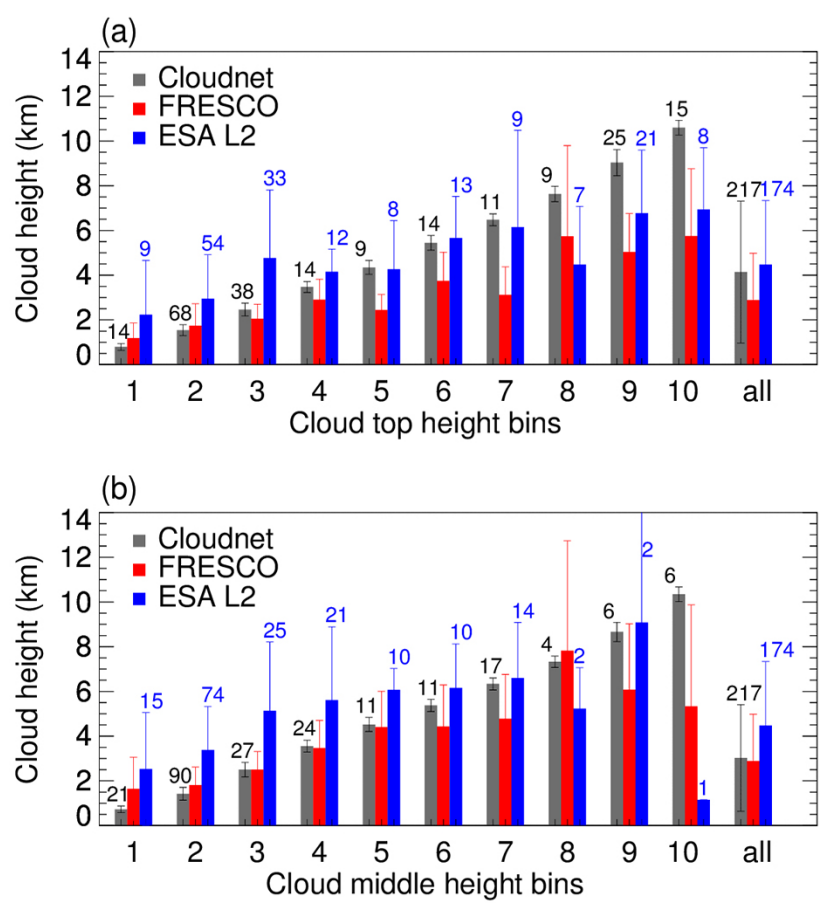

Figure 8. (a) Bar plot of Cloudnet cloud top height, FRESCO cloud height and ESA L2 cloud top height in $1 \mathrm{~km}$ bins of Cloudnet cloud top height, for single-layer clouds. The height ranges of bins $1-10$ are $0-1,1-2,2-3,3-4,4-5,5-6,6-7,7-8,8-10$, and $>10 \mathrm{~km}$. The bin "all" is the mean of bins 1-10. The number above the bar indicates the number of cases; the number of cases for FRESCO is the same as for Cloudnet. The error bar indicates the standard deviation of the data. (b) Same as (a) but for the Cloudnet cloud middle height bins.

of the SCIAMACHY cloud heights for different cloud (top) height ranges. If one would use SCIAMACHY cloud data for some regions dominated by low clouds, then according to Tables A1-A4 in the Appendix the FRESCO cloud product would be a good option. For middle level and high cloud data, the ESA L2 cloud top height may be used. The global comparison of FRESCO cloud height and ESA L2 cloud top height also suggests that SACURA retrieves more middle and high clouds than FRESCO. Depending on different applications, users may prefer cloud top height or cloud height close to the cloud middle. These tables could encourage users to select SCIAMACHY cloud products for their needs.

\subsubsection{Multilayer clouds}

Both the FRESCO and the SACURA algorithms assume a single-layer cloud in the retrieval model. In case of two-layer cloud systems, the FRESCO cloud height is located between the two cloud layers and closest to the optically thicker layer (Wang et al., 2008, 2012; Sneep et al., 2008). The SACURA algorithm retrieves a cloud top height close to the cloud top of the lower cloud if the high cloud is optically thin. If the optical thickness of the high cloud layer is larger than 6 , SACURA most likely retrieves a cloud top height higher than the top of the high cloud (Lelli et al., 2012). This behavior is also expected in the current comparison. Figure 9 shows the scatter plots of FRESCO cloud height vs. Cloudnet cloud top height and Cloudnet cloud middle height, respectively, for multilayer cloud cases. The FRESCO cloud height is indeed closer to the Cloudnet cloud middle height than to the cloud top height, especially for low multilayer clouds. Similar to the single-layer cloud cases, the FRESCO cloud height can be too high (at $15 \mathrm{~km}$ ) for clouds with effective cloud fraction below 0.1. The correlation coefficient between FRESCO cloud height and the Cloudnet cloud top height is 0.509 with a $p$ value of $7.11 \times 10^{-15}$. The correlation coefficient between FRESCO cloud height and the Cloudnet cloud middle height is 0.520 and the $p$ value is $1.55 \times 10^{-15}$. This shows that the correlation between the FRESCO cloud height and the Cloudnet cloud top (middle) height is significant.

The scatter plots of the ESA L2 cloud top height vs. the Cloudnet cloud top height and cloud middle height for multilayer cloud cases (Fig. 10) show more spread than for singlelayer cloud cases (cf. Fig. 6). However, the data points are distributed almost symmetrically along the one-to-one line. The correlation coefficient between the ESA L2 cloud top height and the Cloudnet cloud top (middle) height is 0.330 $(0.399)$ with a $p$ value of $1.11 \times 10^{-5}\left(7.09 \times 10^{-8}\right)$. We can say that the correlation between the ESA L2 cloud top height and the Cloudnet cloud top (middle) height is significant.

The cloud height distributions of multilayer clouds are shown in Fig. 11, as the multilayer analogue of Fig. 7. Here the cases are sorted according to the Cloudnet cloud middle height. The Cloudnet cloud height distribution, indicated by blue-white colors, is normalized to 1 using the maximum occurrence frequency (because of the different temporal and vertical resolutions of the data at Cabauw and Lindenberg, the absolute number of occurrences is different for the two sites). The occurrence frequency can be understood as the relative cloud fraction per altitude bins. The frequency of 1 means fully cloudy. A larger occurrence frequency and a wider distribution indicate more clouds at certain altitudes, which correspond to a large cloud fraction and geometrically thick clouds. As shown in Fig. 11, the FRESCO cloud height agrees well with the peak height of the cloud distribution, up to $5 \mathrm{~km}$. For higher peak heights, the FRESCO cloud height is closer to the lower cloud layers. Most of the FRESCO cloud heights are inside the Cloudnet cloud height distributions. For multilayer clouds Fig. 11 shows that the ESA L2 cloud top height is generally higher than the FRESCO cloud height and lower than the Cloudnet cloud top height, but it does not show a clear relation with the Cloudnet cloud height distribution.

Similar to the single-layer cloud cases, the cloud heights for multilayer clouds have also been divided into height bins according to the Cloudnet cloud top height and cloud middle height, respectively. The results are presented in Fig. 12. 

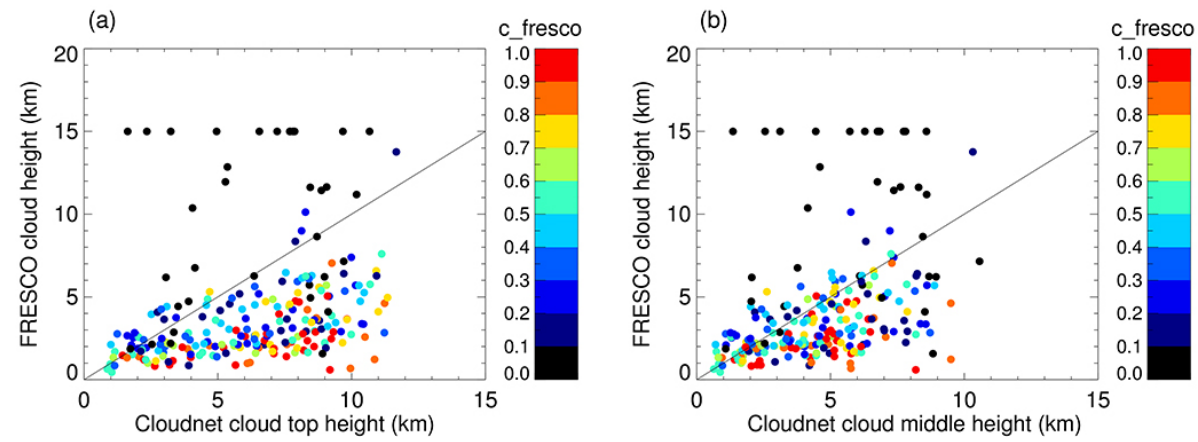

Figure 9. (a) Scatter plot of SCIAMACHY FRESCO cloud height versus Cloudnet cloud top height, for multilayer clouds. (b) Same as (a) but versus Cloudnet cloud middle height. The color of the symbol indicates the FRESCO effective cloud fraction, with the color code given by the vertical bar. The black line is the one-to-one line. For the points with c_fresco $>0.1$ in (a) the correlation coefficient is 0.509 and in (b) the correlation coefficient is 0.520 .
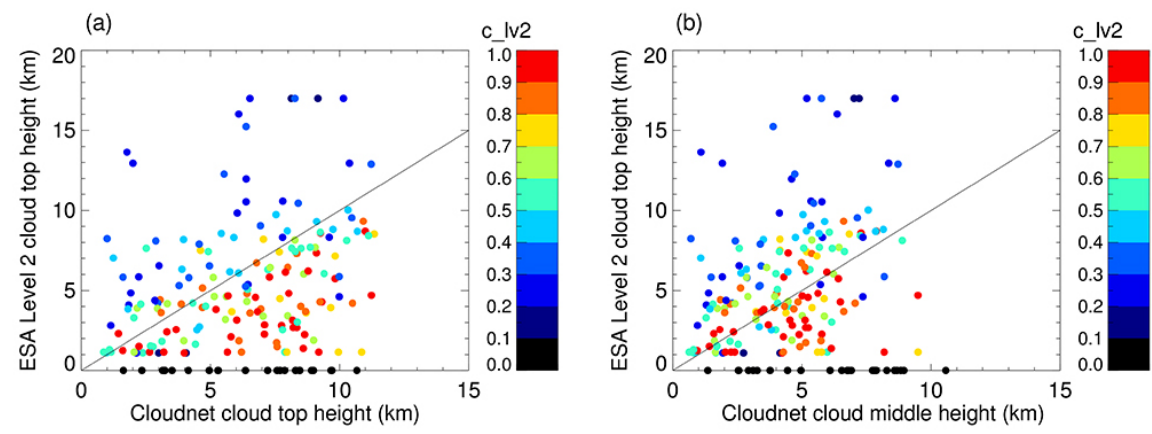

Figure 10. (a) Scatter plot of ESA L2 cloud top height versus Cloudnet cloud top height, for multilayer clouds. (b) Same as (a) but versus Cloudnet cloud middle height. The color of the symbol indicates the ESA L2 cloud fraction, with the color code given by the vertical bar. The black line is the one-to-one line. For the points with c_lv2 $>0.1$ in (a) the correlation coefficient is 0.330 and in (b) the correlation coefficient is 0.399 .

The cloud top heights of multilayer clouds are usually higher than those of single-layer clouds. It appears that the FRESCO cloud height is close to the Cloudnet cloud top height for multilayer low clouds, but we note that only a small percentage of low clouds are multilayer cloud cases: $19 \%$ for the cloud top height bins and $28 \%$ for cloud middle height bins. Here low clouds refer to clouds in the bins $1-3$. The ESA L2 cloud top height for multilayer clouds has about $37 \%$ of cases close to the Cloudnet cloud top height within $1 \mathrm{~km}$. The standard deviation of the differences between the Cloudnet cloud top heights and the ESA L2 cloud top heights is rather large. The statistic results of the comparison between SCIAMACHY cloud heights and Cloudnet cloud heights for multilayer clouds are given in the Appendix in Tables A5-A8.

Comparing Fig. 12 to Fig. 8, the FRESCO cloud height and ESA L2 cloud top height behave consistently for singlelayer and multilayer clouds. However, for the multilayer cloud cases, the differences between SCIAMACHY cloud heights and Cloudnet cloud top and middle heights have larger standard deviations than for single-layer cloud cases.

Multilayer clouds often have an ice cloud layer on top of a water cloud. In this case the ESA L2 COT errors are rather large (Rozanov and Kokhanovsky, 2004), therefore we do not analyze the cloud height differences as a function of COT. The FRESCO and SACURA algorithms are not designed for multilayer clouds; the errors of the SCIAMACHY cloud products can be larger for the multilayer clouds than for the single-layer clouds. Similar to the single-layer cases, Tables A5-A8 in the Appendix may also help the users to choose the proper SCIAMACHY cloud products.

When we divide the Cloudnet cloud top heights into low, middle and high clouds using separation levels at 3 and $6 \mathrm{~km}$, there are $158(37.5 \%)$ low clouds, $88(20.9 \%)$ middle clouds and $175(41.6 \%)$ high clouds out of 421 single- and multilayer cloud cases in this validation data set. The percentages are comparable to those reported by Stubenrauch et al. (2013). The mean differences that we find between the SCIAMACHY cloud heights and the Cloudnet cloud height for all cloud cases may not be representative for the global mean differences. However, the cloud height comparisons for every $1 \mathrm{~km}$ height bin can be considered valid globally, if the clouds are classified in the proper bin. 
Table 3. Comparison of SCIAMACHY cloud (top) heights with Cloudnet cloud (top) height for selected single-layer clouds. Here, the ESA L2 cloud top height retrievals are fully converged. Cloud fractions derived from the Cloudnet data are 1 . The effective cloud fraction is $>0.1$. "All (c_lv2 = 1)" has an additional selection criterion of an ESA L2 cloud fraction of 1.

\begin{tabular}{|c|c|c|c|c|c|c|c|c|c|c|c|}
\hline \multirow{2}{*}{$\begin{array}{l}\text { Cloud } \\
\text { top } \\
\text { bins }(\mathrm{km}) \\
-\end{array}$} & \multicolumn{2}{|c|}{$\begin{array}{c}\text { Cloudnet } \\
\text { cloud top } \\
\text { height }(\mathrm{km})\end{array}$} & \multicolumn{2}{|c|}{$\begin{array}{l}\text { ESA L2 cloud } \\
\text { top height } \\
(\mathrm{km})\end{array}$} & \multicolumn{2}{|c|}{$\begin{array}{l}\text { FRESCO cloud } \\
\text { height }(\mathrm{km})\end{array}$} & \multicolumn{2}{|c|}{$\begin{array}{l}\text { Cloudnet } \\
\text { cloud middle } \\
\text { height }(\mathrm{km})\end{array}$} & \multicolumn{2}{|c|}{$\begin{array}{c}\text { ESA L2 Cloud } \\
\text { optical } \\
\text { thickness }\end{array}$} & \multirow[t]{2}{*}{$\begin{array}{r}\text { No. of } \\
\text { cases }\end{array}$} \\
\hline & mean & $\sigma$ & mean & $\sigma$ & mean & $\sigma$ & mean & $\sigma$ & mean & $\sigma$ & \\
\hline $1-3$ & 2.18 & 0.47 & 5.01 & 2.4 & 2.5 & 1.5 & 1.58 & 0.36 & 15.83 & 7.35 & 13 \\
\hline $3-6$ & 4.32 & 1.01 & 5.16 & 1.21 & 2.90 & 0.8 & 2.81 & 0.60 & 26.86 & 18.92 & 13 \\
\hline$>6$ & 8.55 & 1.35 & 6.86 & 1.31 & 4.46 & 1.17 & 4.96 & 0.80 & 41.73 & 26.04 & 18 \\
\hline All & 5.42 & 2.95 & 5.81 & 1.87 & 3.42 & 1.47 & 3.32 & 1.58 & 29.68 & 22.45 & 44 \\
\hline All (c_lv2 = 1) & 8.04 & 2.44 & 5.97 & 1.25 & 4.15 & 0.94 & 4.61 & 1.20 & 50.47 & 17.62 & 8 \\
\hline
\end{tabular}

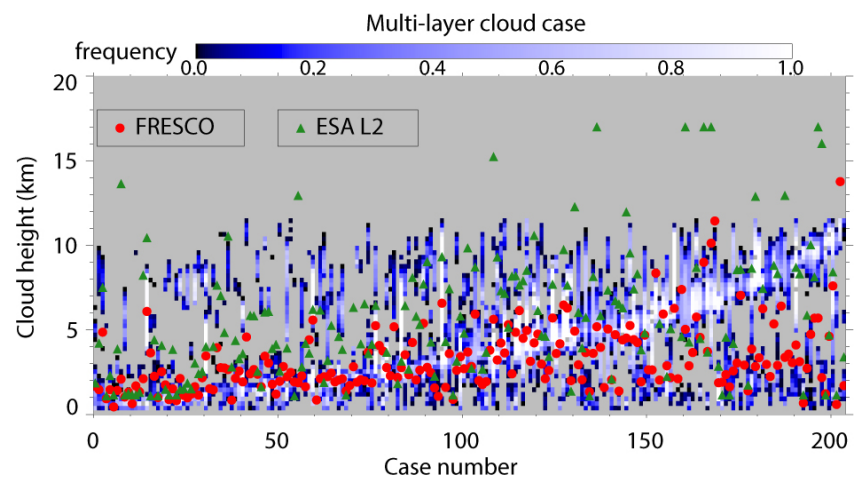

Figure 11. Comparison between the SCIAMACHY ESA L2 cloud top height, the FRESCO cloud height, and the Cloudnet cloud height distribution for multilayer clouds. The cases are sorted according to the Cloudnet cloud middle height. The Cloudnet cloud height distribution is normalized to 1 and indicated with a bluewhite color (color code given by the horizontal bar). Here the cases with FRESCO effective cloud fraction below 0.1 are excluded.

\subsubsection{Selected cloud cases}

The above evaluations have used all the FRESCO cloud heights and ESA L2 cloud top heights provided in the corresponding products. According to the cloud flag in the ESA L2 data, the fully converged cases should have the smallest error. The FRESCO and SACURA algorithms are more accurate for optically thick clouds. Therefore we applied more strict selection criteria in the comparison; namely, singlelayer clouds, fully cloudy during $1 \mathrm{~h}$ at SCIAMACHY overpass time at the collocated Cloudnet site (geometric cloud fraction of 1), fully converged in SACURA retrievals and effective cloud fractions $>0.1$. Using these selection criteria for Cloudnet, FRESCO and ESA L2 cloud products, there are 44 collocated cases. The results are shown in Table 3. For the 44 cases, the mean Cloudnet cloud top height is $5.4 \mathrm{~km}$ and the Cloudnet cloud middle height is $3.3 \mathrm{~km}$. The mean FRESCO cloud height is $2.0 \mathrm{~km}$ lower than the Cloudnet cloud top height and $0.1 \mathrm{~km}$ higher than the Cloudnet cloud middle height. The mean ESA L2 cloud top height is $0.4 \mathrm{~km}$ higher than the Cloudnet cloud top height and $2.5 \mathrm{~km}$ higher than the Cloudnet cloud middle height. The mean ESA L2 cloud optical thickness is 29.7 with a standard deviation of 22.5. The mean FRESCO effective cloud fraction is 0.7 with a standard deviation of 0.2 . The COT and effective cloud fraction values both suggest that these 44 cases are mainly optically thick clouds. These results are consistent with the comparisons for the single-layer cloud cases in Sect. 4.2.1, where the difference between ESA L2 cloud top height and Cloudnet cloud top height is $0.4 \mathrm{~km}$ (see Table A2 in the Appendix) and the difference between FRESCO cloud height and Cloudnet cloud middle height is $-0.1 \mathrm{~km}$ (see Table A3 in the Appendix).

In the 44 cases, there are 8 cases having an ESA L2 cloud fraction of 1 . The comparison for these 8 cases is presented in Table 3 as "All (c_lv2 $=1)$ ". These cases are included in Figs. 5 and 6 for c_lv2 $=1$ and c_fresco $=1$, respectively. Most of these cases are optically and geometrically thick ice clouds; their mean cloud top height is $8 \mathrm{~km}$, whereas the water clouds are below $4 \mathrm{~km}$ (see Figs. $5 \mathrm{~b}$ and $6 \mathrm{~b})$. The FRESCO cloud height is still close to the Cloudnet cloud middle height and the ESA L2 cloud top height is close to the Cloudnet cloud top height, although slightly lower. SACURA retrieves cloud top height more accurately for single-layer, optically thick water clouds (see Fig. 6b, c_lv2 = 1 cases). For the ice clouds, the SACURA algorithm may retrieve a lower cloud top height due to the assumptions on the cloud scattering phase function and the cloud water content.

\section{Conclusions}

Two SCIAMACHY $\mathrm{O}_{2}$ A band cloud height products, FRESCO (version 6) and ESA L2 (version 5.02) have been compared globally using selected data from August 2002 to March 2012. The FRESCO effective cloud fraction and ESA L2 cloud fraction have good agreement, except at effective cloud fractions $<0.2$. On average, the ESA L2 cloud fraction 

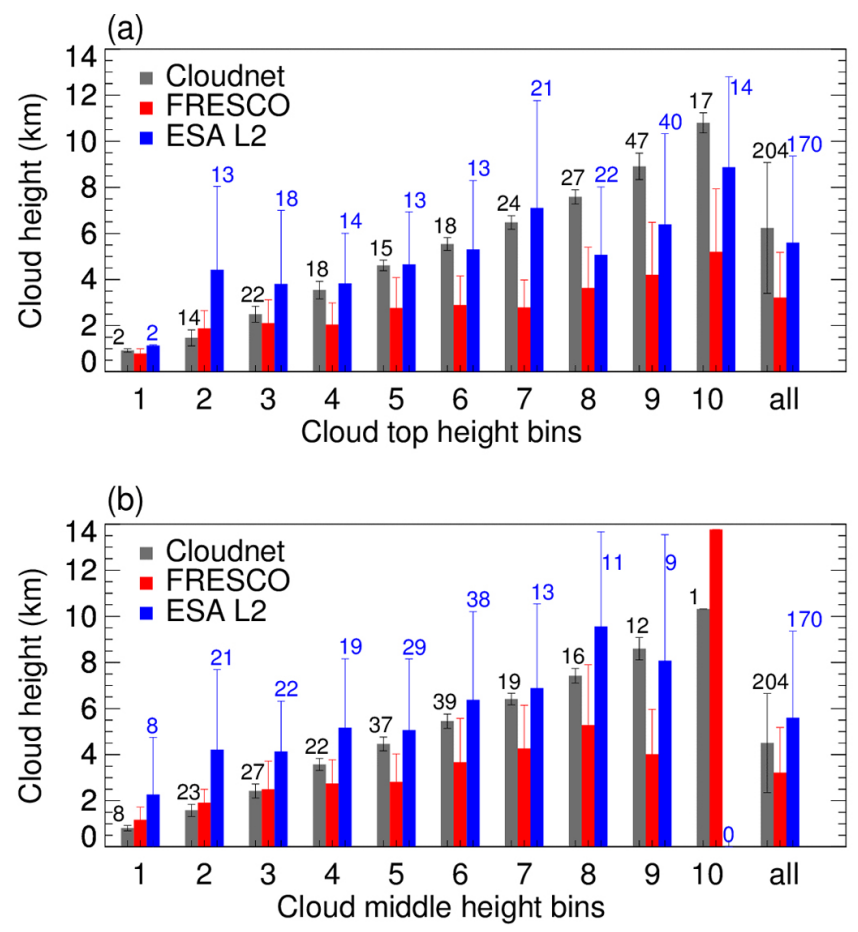

Figure 12. (a) Bar plot of Cloudnet cloud top height, FRESCO cloud height and ESA L2 cloud top height in $1 \mathrm{~km}$ bins of Cloudnet cloud top height, for multilayer clouds. The height ranges of bins 110 are $0-1,1-2,2-3,3-4,4-5,5-6,6-7,7-8,8-10$, and $>10 \mathrm{~km}$. The bin "all" is the mean of bins $1-10$. The number above the bar indicates the number of cases; the number of cases for FRESCO is the same as for Cloudnet. The error bar indicates the standard deviation of the data. (b) Same as (a) but for the Cloudnet cloud middle height bins.

is 0.02 smaller than the FRESCO effective cloud fraction with a standard deviation of 0.1. The SCIAMACHY ESA L2 cloud top height is about $0.6 \mathrm{~km}$ higher than the FRESCO cloud height with a standard deviation of $2.2 \mathrm{~km}$. The difference between the FRESCO cloud height and the ESA L2 cloud top height is smaller for optically thick clouds and larger for optically thin clouds. This also depends on the geometric thickness. Simulations of FRESCO cloud height retrievals are performed for different cloud heights and optical thicknesses to interpret the validation results for the SCIAMACHY FRESCO cloud height. The SCIAMACHY cloud products are stable over time, which suggests that the SCIAMACHY L1 7.04 data have a good degradation correction.

The SCIAMACHY cloud height products have been validated using the Cloudnet radar/lidar classification and cloud boundaries at Cabauw and Lindenberg, from January 2003 to December 2011. The collocated cases are separated into single-layer clouds and multilayer clouds according to the height distribution of the radar/lidar backscatter signals during $1 \mathrm{~h}( \pm 30 \mathrm{~min})$ around the SCIAMACHY overpass time. In total we found 693 collocated cases. After excluding the cases with (effective) cloud fractions smaller than 0.1, 421 cases remain; of which 217 cases are single-layer clouds and 204 cases are multilayer clouds.

For single-layer clouds, the difference between FRESCO cloud height and Cloudnet cloud top height is $-1.3 \mathrm{~km}$ with a standard deviation of $2.3 \mathrm{~km}$; the difference between ESA L2 cloud top height and Cloudnet cloud top height is $0.4 \mathrm{~km}$ with a standard deviation of $3.1 \mathrm{~km}$. For single-layer clouds, the difference between FRESCO cloud height and Cloudnet cloud middle height is $-0.1 \mathrm{~km}$ with a standard deviation of $1.9 \mathrm{~km}$; the difference between ESA L2 cloud top height and Cloudnet cloud middle height is $1.7 \mathrm{~km}$ with a standard deviation of $2.7 \mathrm{~km}$. The evaluation of the ESA L2 fully converged single-layer cases shows consistent results with those mentioned above.

The FRESCO cloud height is close to the Cloudnet cloud middle height for both single-layer and multilayer clouds. FRESCO uses a Lambertian cloud model in the forward model and in the retrievals, therefore the light path used in FRESCO is shorter than the real light path in scattering clouds. In order to compensate, the FRESCO-retrieved cloud height is lower than the real cloud top height. For cases with a relatively bright surface albedo, there are too many scatterings and reflections between the cloud and the surface, for which light path is not included in FRESCO. Therefore, the FRESCO-retrieved cloud height has more scatter over a bright surface than over a dark surface, especially for optically thin clouds.

The ESA L2 cloud top height appears to be close to the Cloudnet cloud top height for middle level clouds, higher than the Cloudnet cloud top height for low clouds, and lower than the Cloudnet cloud top height for high clouds. For the single-layer low clouds, based on the ESA L2 cloud optical thickness, the ESA L2 cloud top height has a larger error for optically thin clouds than for optically thick clouds. Due to its principle, the SACURA algorithm is more suitable for optically thick clouds. The accuracy of the SACURA algorithm depends on the accuracy of the geometric cloud fraction; therefore the accuracy of the input cloud fraction for SACURA may require further evaluation.

The validation data are analyzed for single-layer clouds and multilayer clouds for $1 \mathrm{~km}$ height bins. We find that the error of the FRESCO cloud height is $<1 \mathrm{~km}$ for clouds below $6 \mathrm{~km}$, whereas the ESA L2 cloud top height has an error of $<1 \mathrm{~km}$ for clouds at $3-7 \mathrm{~km}$, but it has a large scatter.

In the validation data set for Cabauw and Lindenberg, there appears to be more low clouds than high clouds (including high clouds on top of low clouds). This leads to a larger percentage of FRESCO cloud heights close to the Cloudnet measurements, while the percentage of results for the ESA L2 cloud top height is smaller. However, from the global FRESCO cloud height distribution and ESA L2 cloud top height distribution from the SCIAMACHY data set, covering all latitudes and all months, it appears that both cloud height products show more low clouds than high clouds. 
Based on other satellite cloud height products, globally, $42 \%$ of all clouds are high clouds and about $42 \%$ of all clouds are single-layer low-level clouds (Stubenrauch et al., 2013). We may conclude that, as a global cloud product, FRESCO cloud height is accurate for low clouds, whereas the ESA L2 cloud top height is more accurate for middle level clouds.

The cloud height distributions at Cabauw and Lindenberg, where the SCIAMACHY cloud height validation has been performed, cannot be considered as being representative for the entire globe. However, the validation results of this paper in terms of the reported accuracy of the SCIAMACHY cloud product per $1 \mathrm{~km}$ height bin can be translated into an estimate of the SCIAMACHY cloud height accuracy at other locations in the world. For such an estimate the true (or climatological mean) vertical distribution of clouds at other locations would be required. 
Appendix A: Statistical results of comparisons between

SCIAMACHY cloud heights and Cloudnet cloud heights

for single-layer and multilayer clouds in $1 \mathrm{~km}$ cloud bins

Table A1. Comparison of SCIAMACHY FRESCO cloud height with Cloudnet cloud top height for single-layer clouds.

\begin{tabular}{lrrrrrrr}
\hline $\begin{array}{l}\text { Cloud } \\
\text { top } \\
\text { bins }(\mathrm{km})\end{array}$ & \multicolumn{2}{c}{$\begin{array}{l}\text { Cloudnet } \\
\text { cloud top } \\
\text { height }(\mathrm{km})\end{array}$} & \multicolumn{2}{c}{$\begin{array}{c}\text { FRESCO cloud } \\
\text { height }(\mathrm{km})\end{array}$} & \multicolumn{2}{c}{$\begin{array}{c}\text { FRESCO }- \\
\text { Cloudnet }(\mathrm{km})\end{array}$} & $\begin{array}{r}\text { No. of } \\
\text { cases }\end{array}$ \\
\hline & mean & $\sigma$ & mean & $\sigma$ & mean & $\sigma$ & \\
$0-1$ & 0.79 & 0.15 & 1.19 & 0.67 & 0.40 & 0.65 & 14 \\
$1-2$ & 1.54 & 0.24 & 1.74 & 0.98 & 0.20 & 1.01 & 68 \\
$2-3$ & 2.46 & 0.29 & 2.05 & 0.65 & -0.41 & 0.70 & 38 \\
$3-4$ & 3.47 & 0.24 & 2.90 & 0.92 & -0.57 & 0.81 & 14 \\
$4-5$ & 4.35 & 0.31 & 2.44 & 0.69 & -1.90 & 0.76 & 9 \\
$5-6$ & 5.45 & 0.33 & 3.75 & 1.28 & -1.70 & 1.39 & 14 \\
$6-7$ & 6.48 & 0.26 & 3.12 & 1.26 & -3.36 & 1.27 & 11 \\
$7-8$ & 7.63 & 0.35 & 5.74 & 4.06 & -1.89 & 4.09 & 9 \\
$8-10$ & 9.03 & 0.58 & 5.04 & 1.72 & -3.99 & 1.96 & 25 \\
$>10$ & 10.60 & 0.33 & 5.75 & 3.01 & -4.85 & 2.99 & 15 \\
\hline All & 4.14 & 3.17 & 2.89 & 2.10 & -1.25 & 2.31 & 217 \\
\hline
\end{tabular}

Table A2. Comparison of ESA L2 cloud top height with Cloudnet cloud top height for single-layer clouds.

\begin{tabular}{lrrrrrrr}
\hline $\begin{array}{l}\text { Cloud } \\
\begin{array}{l}\text { top bins } \\
(\mathrm{km})\end{array}\end{array}$ & $\begin{array}{c}\text { Cloudnet } \\
\text { top height } \\
(\mathrm{km})\end{array}$ & $\begin{array}{c}\text { ESA L2 cloud } \\
\text { top height } \\
(\mathrm{km})\end{array}$ & $\begin{array}{r}\text { ESA L2 }- \\
\text { Cloudnet }(\mathrm{km})\end{array}$ & $\begin{array}{r}\text { No. of } \\
\text { cases }\end{array}$ \\
\hline & mean & $\sigma$ & mean & $\sigma$ & mean & $\sigma$ & \\
$0-1$ & 0.75 & 0.16 & 2.24 & 2.42 & 1.49 & 2.40 & 9 \\
$1-2$ & 1.53 & 0.23 & 2.95 & 1.97 & 1.42 & 1.98 & 54 \\
$2-3$ & 2.49 & 0.29 & 4.77 & 3.04 & 2.28 & 3.05 & 33 \\
$3-4$ & 3.43 & 0.24 & 4.15 & 1.02 & 0.72 & 1.14 & 12 \\
$4-5$ & 4.31 & 0.31 & 4.27 & 2.17 & -0.04 & 2.16 & 8 \\
$5-6$ & 5.40 & 0.30 & 5.66 & 1.86 & 0.25 & 1.93 & 13 \\
$6-7$ & 6.50 & 0.26 & 6.15 & 4.33 & -0.35 & 4.48 & 9 \\
$7-8$ & 7.62 & 0.39 & 4.47 & 2.61 & -3.15 & 2.69 & 7 \\
$8-10$ & 9.00 & 0.62 & 6.77 & 2.82 & -2.23 & 3.02 & 21 \\
$>10$ & 10.47 & 0.32 & 6.93 & 2.77 & -3.54 & 2.81 & 8 \\
\hline All & 4.03 & 3.00 & 4.47 & 2.86 & 0.44 & 3.07 & 174 \\
\hline
\end{tabular}


Table A3. Comparison of SCIAMACHY FRESCO cloud height with Cloudnet cloud middle height for single-layer clouds.

\begin{tabular}{lrrrrrrr}
\hline $\begin{array}{l}\text { Cloud } \\
\text { middle } \\
\text { bins }(\mathrm{km})\end{array}$ & \multicolumn{2}{c}{$\begin{array}{c}\text { Cloudnet } \\
\text { middle } \\
\text { height }(\mathrm{km})\end{array}$} & \multicolumn{2}{c}{$\begin{array}{c}\text { FRESCO } \\
\text { cloud } \\
\text { height }(\mathrm{km})\end{array}$} & $\begin{array}{c}\text { FRESCO }- \\
\text { Cloudnet } \\
(\mathrm{km})\end{array}$ & $\begin{array}{r}\text { No. of } \\
\text { cases }\end{array}$ \\
\hline & mean & $\sigma$ & mean & $\sigma$ & mean & $\sigma$ & \\
$0-1$ & 0.73 & 0.15 & 1.64 & 1.42 & 0.91 & 1.37 & 21 \\
$1-2$ & 1.42 & 0.29 & 1.81 & 0.81 & 0.39 & 0.77 & 90 \\
$2-3$ & 2.50 & 0.32 & 2.51 & 0.80 & 0.01 & 0.79 & 27 \\
$3-4$ & 3.55 & 0.27 & 3.47 & 1.24 & -0.09 & 1.20 & 24 \\
$4-5$ & 4.52 & 0.32 & 4.40 & 1.61 & -0.12 & 1.56 & 11 \\
$5-6$ & 5.37 & 0.27 & 4.43 & 1.86 & -0.95 & 1.88 & 11 \\
$6-7$ & 6.33 & 0.27 & 4.78 & 1.98 & -1.55 & 2.02 & 17 \\
$7-8$ & 7.32 & 0.25 & 7.82 & 4.93 & 0.49 & 4.80 & 4 \\
$8-10$ & 8.66 & 0.43 & 6.08 & 2.94 & -2.58 & 3.18 & 6 \\
$>10$ & 10.34 & 0.33 & 5.33 & 4.54 & -5.01 & 4.60 & 6 \\
\hline All & 3.02 & 2.39 & 2.89 & 2.10 & -0.14 & 1.88 & 217 \\
\hline
\end{tabular}

Table A4. Comparison of SCIAMACHY ESA L2 cloud top height with Cloudnet cloud middle height for single-layer clouds.

\begin{tabular}{lrrrrrrr}
\hline $\begin{array}{l}\text { Cloud } \\
\text { middle } \\
\text { bins }(\mathrm{km})\end{array}$ & $\begin{array}{c}\text { Cloudnet } \\
\text { middle } \\
\text { height }(\mathrm{km})\end{array}$ & $\begin{array}{c}\text { ESA L2 } \\
\text { cloud top } \\
\text { height }(\mathrm{km})\end{array}$ & $\begin{array}{c}\text { ESA L2 } \\
\text { Cloudnet } \\
(\mathrm{km})\end{array}$ & $\begin{array}{r}\text { No. of } \\
\text { cases }\end{array}$ \\
\hline & mean & $\sigma$ & mean & $\sigma$ & mean & $\sigma$ & \\
$0-1$ & 0.70 & 0.16 & 2.53 & 2.52 & 1.83 & 2.50 & 15 \\
$1-2$ & 1.40 & 0.28 & 3.38 & 1.95 & 1.97 & 1.87 & 74 \\
$2-3$ & 2.53 & 0.32 & 5.14 & 3.08 & 2.61 & 3.13 & 25 \\
$3-4$ & 3.56 & 0.24 & 5.61 & 3.28 & 2.05 & 3.19 & 21 \\
$4-5$ & 4.48 & 0.30 & 6.07 & 0.96 & 1.59 & 0.87 & 10 \\
$5-6$ & 5.36 & 0.28 & 6.16 & 1.97 & 0.80 & 1.96 & 10 \\
$6-7$ & 6.36 & 0.28 & 6.60 & 2.49 & 0.24 & 2.56 & 14 \\
$7-8$ & 7.11 & 0.03 & 5.23 & 1.83 & -1.89 & 1.87 & 2 \\
$8-10$ & 8.62 & 0.70 & 9.08 & 11.21 & 0.46 & 11.90 & 2 \\
$>10$ & 10.34 & - & 1.15 & - & -9.19 & - & 1 \\
\hline All & 2.77 & 1.97 & 4.47 & 2.86 & 1.71 & 2.71 & 174 \\
\hline
\end{tabular}

Table A5. Comparison of SCIAMACHY FRESCO cloud height with Cloudnet cloud top height for multilayer clouds.

\begin{tabular}{lrrrrrrr}
\hline $\begin{array}{l}\text { Cloud } \\
\text { top bins } \\
(\mathrm{km})\end{array}$ & \multicolumn{2}{c}{$\begin{array}{c}\text { Cloudnet } \\
\text { cloud top } \\
\text { height }(\mathrm{km})\end{array}$} & $\begin{array}{c}\text { FRESCO } \\
\text { cloud } \\
\text { height }(\mathrm{km})\end{array}$ & $\begin{array}{c}\text { FRESCO }- \\
\text { Cloudnet } \\
(\mathrm{km})\end{array}$ & $\begin{array}{r}\text { No. of } \\
\text { cases }\end{array}$ \\
\hline & mean & $\sigma$ & mean & $\sigma$ & mean & $\sigma$ & \\
$0-1$ & 0.92 & 0.07 & 0.78 & 0.21 & -0.14 & 0.13 & 2 \\
$1-2$ & 1.47 & 0.35 & 1.88 & 0.77 & 0.42 & 0.64 & 14 \\
$2-3$ & 2.50 & 0.35 & 2.11 & 1.02 & -0.39 & 0.97 & 22 \\
$3-4$ & 3.54 & 0.38 & 2.05 & 0.94 & -1.50 & 1.08 & 18 \\
$4-5$ & 4.61 & 0.23 & 2.76 & 1.32 & -1.85 & 1.33 & 15 \\
$5-6$ & 5.54 & 0.28 & 2.89 & 1.25 & -2.65 & 1.28 & 18 \\
$6-7$ & 6.48 & 0.29 & 2.79 & 1.19 & -3.68 & 1.20 & 24 \\
$7-8$ & 7.58 & 0.31 & 3.63 & 1.77 & -3.95 & 1.73 & 27 \\
$8-10$ & 8.91 & 0.57 & 4.20 & 2.28 & -4.71 & 2.43 & 47 \\
$>10$ & 10.80 & 0.44 & 5.20 & 2.74 & -5.60 & 2.57 & 17 \\
\hline All & 6.24 & 2.84 & 3.21 & 1.96 & -3.02 & 2.50 & 204 \\
\hline
\end{tabular}


Table A6. Comparison of SCIAMACHY ESA L2 cloud top height with Cloudnet cloud top height for multilayer clouds.

\begin{tabular}{lrrrrrrr}
\hline $\begin{array}{l}\text { Cloud } \\
\text { top bins } \\
(\mathrm{km})\end{array}$ & \multicolumn{2}{c}{$\begin{array}{c}\text { Cloudnet } \\
\text { cloud top } \\
\text { height }(\mathrm{km})\end{array}$} & \multicolumn{2}{c}{$\begin{array}{c}\text { ESA L2 } \\
\text { cloud top } \\
\text { height }(\mathrm{km})\end{array}$} & $\begin{array}{c}\text { ESA L2 } \\
\text { Cloudnet } \\
(\mathrm{km})\end{array}$ & $\begin{array}{r}\text { No. of } \\
\text { cases }\end{array}$ \\
\hline & mean & $\sigma$ & mean & $\sigma$ & mean & $\sigma$ & \\
$0-1$ & 0.92 & 0.07 & 1.13 & 0.03 & 0.21 & 0.11 & 2 \\
$1-2$ & 1.44 & 0.34 & 4.42 & 3.62 & 2.99 & 3.53 & 13 \\
$2-3$ & 2.49 & 0.36 & 3.81 & 3.20 & 1.32 & 3.26 & 18 \\
$3-4$ & 3.52 & 0.39 & 3.83 & 2.18 & 0.32 & 2.16 & 14 \\
$4-5$ & 4.56 & 0.27 & 4.66 & 2.28 & 0.10 & 2.16 & 13 \\
$5-6$ & 5.56 & 0.26 & 5.31 & 2.99 & -0.25 & 3.02 & 13 \\
$6-7$ & 6.43 & 0.29 & 7.10 & 4.66 & 0.67 & 4.69 & 21 \\
$7-8$ & 7.59 & 0.33 & 5.07 & 2.95 & -2.52 & 2.96 & 22 \\
$8-10$ & 8.92 & 0.60 & 6.39 & 3.94 & -2.52 & 4.05 & 40 \\
$>10$ & 10.75 & 0.40 & 8.88 & 3.93 & -1.87 & 4.08 & 14 \\
\hline All & 6.21 & 2.87 & 5.60 & 3.76 & -0.61 & 3.91 & 170 \\
\hline
\end{tabular}

Table A7. Comparison of SCIAMACHY FRESCO cloud height with Cloudnet cloud middle layer height for multilayer clouds.

\begin{tabular}{lrrrrrrr}
\hline $\begin{array}{l}\text { Cloud } \\
\text { middle } \\
\text { bins }(\mathrm{km})\end{array}$ & \multicolumn{2}{c}{$\begin{array}{c}\text { Cloudnet } \\
\text { cloud middle } \\
\text { height }(\mathrm{km})\end{array}$} & \multicolumn{2}{c}{$\begin{array}{c}\text { FRESCO } \\
\text { cloud } \\
\text { height }(\mathrm{km})\end{array}$} & $\begin{array}{c}\text { FRESCO } \\
\text { Cloudnet } \\
(\mathrm{km})\end{array}$ & $\begin{array}{r}\text { No. of } \\
\text { cases }\end{array}$ \\
\hline & mean & $\sigma$ & mean & $\sigma$ & mean & $\sigma$ & \\
$0-1$ & 0.81 & 0.11 & 1.17 & 0.56 & 0.36 & 0.60 & 8 \\
$1-2$ & 1.58 & 0.27 & 1.92 & 0.58 & 0.34 & 0.73 & 23 \\
$2-3$ & 2.42 & 0.30 & 2.49 & 1.23 & 0.07 & 1.24 & 27 \\
$3-4$ & 3.57 & 0.26 & 2.75 & 1.03 & -0.82 & 1.01 & 22 \\
$4-5$ & 4.46 & 0.30 & 2.82 & 1.22 & -1.65 & 1.21 & 37 \\
$5-6$ & 5.45 & 0.31 & 3.67 & 1.90 & -1.78 & 1.98 & 39 \\
$6-7$ & 6.41 & 0.25 & 4.26 & 1.88 & -2.15 & 1.86 & 19 \\
$7-8$ & 7.43 & 0.32 & 5.28 & 2.62 & -2.14 & 2.71 & 16 \\
$8-10$ & 8.59 & 0.49 & 4.01 & 1.95 & -4.58 & 2.10 & 12 \\
$>10$ & 10.32 & - & 13.76 & - & 3.44 & - & 1 \\
\hline All & 4.50 & 2.15 & 3.21 & 1.96 & -1.29 & 2.02 & 204 \\
\hline
\end{tabular}

Table A8. Comparison of SCIAMACHY ESA L2 cloud top height with Cloudnet cloud middle height for multilayer clouds.

\begin{tabular}{lrrrrrrr}
\hline $\begin{array}{l}\text { Cloud } \\
\text { middle } \\
\text { bins }(\mathrm{km})\end{array}$ & $\begin{array}{c}\text { Cloudnet } \\
\text { cloud middle } \\
\text { height }(\mathrm{km})\end{array}$ & $\begin{array}{c}\text { ESA L2 } \\
\text { cloud top } \\
\text { height }(\mathrm{km})\end{array}$ & $\begin{array}{c}\text { ESA L2 } \\
\text { Cloudnet } \\
(\mathrm{km})\end{array}$ & $\begin{array}{r}\text { No. of } \\
\text { cases }\end{array}$ \\
\hline & mean & $\sigma$ & mean & $\sigma$ & mean & $\sigma$ & \\
$0-1$ & 0.81 & 0.12 & 2.27 & 2.48 & 1.46 & 2.51 & 8 \\
$1-2$ & 1.58 & 0.26 & 4.21 & 3.48 & 2.63 & 3.56 & 21 \\
$2-3$ & 2.45 & 0.29 & 4.13 & 2.18 & 1.69 & 2.08 & 22 \\
$3-4$ & 3.58 & 0.27 & 5.16 & 3.00 & 1.59 & 2.96 & 19 \\
$4-5$ & 4.44 & 0.29 & 5.06 & 3.09 & 0.63 & 3.10 & 29 \\
$5-6$ & 5.46 & 0.31 & 6.38 & 3.83 & 0.92 & 3.86 & 38 \\
$6-7$ & 6.40 & 0.24 & 6.88 & 3.66 & 0.48 & 3.63 & 13 \\
$7-8$ & 7.37 & 0.29 & 9.56 & 4.12 & 2.19 & 4.19 & 11 \\
$8-10$ & 8.68 & 0.53 & 8.07 & 5.47 & -0.61 & 5.64 & 9 \\
$>10$ & - & - & - & - & - & - & 0 \\
\hline All & 4.35 & 2.09 & 5.60 & 3.76 & 1.25 & 3.50 & 170 \\
\hline
\end{tabular}


Acknowledgements. We would like to thank our KNMI colleagues Ronald van der A for processing FRESCO data and Henk Klein Baltink and Dave Donovan for help with Cloudnet data. We acknowledge the ESA for the provision of SCIAMACHY L1 and L2 data. We acknowledge the Cloudnet project (European Union contract EVK2-2000-00611) for providing the target classification product, which was produced by the University of Reading and KNMI using measurements from the Cabauw Experimental Site for Atmospheric Research (CESAR), and DWD (German Weather Service) using measurements from the Lindenberg site. This work was supported by the Netherlands Space Office (NSO) as part of the SCIA-Visie project. We are grateful to two anonymous referees and to L. Lelli (Uni-Bremen) for useful comments and suggestions.

Edited by: A. Kokhanovsky

\section{References}

Anderson, G. P., Clough, S. A., Kneizys, F. X., Chetwynd, J. H., and Shettle, E. P.: AFGL atmospheric constituent profiles, Tech. Rep. AFGL-TR-86-0110, Air Force Geophys. Lab., Hanscom AFB, MA, 1986.

Boersma, K. F., Eskes, H. J., and Brinksma, E. J.: Error analysis for tropospheric $\mathrm{NO}_{2}$ retrieval from space, J. Geophys. Res., 109, D04311, doi:10.1029/2003JD003962, 2004.

Bovensmann, H., Burrows, J. P., Buchwitz, M., Frerick, J., Noel, S., Rozanov, V. V., Chance, K. V., and Goede, A. P. H.: SCIAMACHY: mission objectives and measurement modes, J. Atmos. Sci., 56, 127-150, 1999.

Bramstedt, K.: Calculation of SCIAMACHY M-Factors, Technical Note, IFE-SCIA-TN-2007-01-CalcMFactor, Issue: 1, available at: http://www.iup.uni-bremen.de/sciamachy/mfactors/ (last access: 10 January 2014), 2008.

Buchwitz, M., Rozanov, V. V., and Burrows, J. P.: A correlated $k$ distribution scheme for overlapping gases suitable for retrieval of atmospheric constituents from moderate resolution radiance measurements in the visible/near-infrared spectral region, J. Geophys. Res., 105, 15247-15262, 2000.

Bucsela, E. J., Celarier, E. A., Wenig, M. O., Gleason, J. F., Veefkind, J. P., Boersma, K. F., and Brinksma, E. J.: Algorithm for $\mathrm{NO}_{2}$ vertical column retrieval from the Ozone Monitoring Instrument, IEEE T. Geosci. Remote Sens., 44, 1245-1258, 2006.

De Haan, J. F., Bosma, P. B., and Hovenier, J. W.: The adding method for multiple scattering calculations of polarized light, Astron. Astrophys., 183, 371-391, 1987.

Desmons, M., Ferlay, N., Parol, F., Mcharek, L., and Vanbauce, C.: Improved information about the vertical location and extent of monolayer clouds from POLDER3 measurements in the oxygen A-band, Atmos. Meas. Tech., 6, 2221-2238, doi:10.5194/amt-62221-2013, 2013.

Feigelson, E. M. (Ed.): Radiation in a Cloudy Atmosphere, Gidrometeoizdat, Leningrad, 280 pp., 1981.

Ferlay, N., Thieuleux, F., Cornet, C., Davis, A. B., Dubuisson, P., Ducos, F., Parol, F., Riedi, J., and Vanbauce, C.: Toward new inferences about cloud structures from multidirectional measurements in the oxygen A band: middleof cloud pressure and cloud geometrical thickness from POLDER-3/PARASOL, J. Appl. Meteorol. Clim., 49, 24922507, doi:10.1175/2010JAMC2550.1, 2010.
Hogan, R. J. and O'Connor, E. J.: Facilitating cloud radar and lidar algorithms: the Cloudnet Instrument Synergy/Target Categorization product, available at: http: //www.met.rdg.ac.uk/ swrhgnrj/publications/categorization.pdf (last access: 30 September 2013), 2004.

Illingworth, A. J., Hogan, R. J., O'Connor, E. J., Bouniol, D., Brooks, M. E., Delanoe, J., Donovan, D. P., Eastment, J. D., Gaussiat, N., Goddard, J. W. F., Haeffelin, M., Klein Baltink, H., Krasnov, O. A., Pelon, J., Piriou, J.-M., Protat, A., Russchenberg, H. W. J., Seifert, A., Tompkins, A. M., van Zadelhoff, G.-J., Vinit, F., Willen, U., Wilson, D. R., and Wrench, C. L.: Cloudnet - continuous evaluation of cloud profiles in seven operational models using ground-based observations, B. Am. Meteorol. Soc., 88, 883-898, 2007.

Joiner, J., Vasilkov, A. P., Bhartia, P. K., Wind, G., Platnick, S., and Menzel, W. P.: Detection of multi-layer and vertically-extended clouds using A-train sensors, Atmos. Meas. Tech., 3, 233-247, doi:10.5194/amt-3-233-2010, 2010.

Joiner, J., Vasilkov, A. P., Gupta, P., Bhartia, P. K., Veefkind, P., Sneep, M., de Haan, J., Polonsky, I., and Spurr, R.: Fast simulators for satellite cloud optical centroid pressure retrievals; evaluation of OMI cloud retrievals, Atmos. Meas. Tech., 5, 529-545, doi:10.5194/amt-5-529-2012, 2012.

Koelemeijer, R. B. A., Stammes, P., Hovenier, J. W., and de Haan, J. F.: A fast method for retrieval of cloud parameters using oxygen A band measurements from the Global Ozone Monitoring Experiment, J. Geophys. Res., 106, 3475-3490, 2001.

Kokhanovsky, A. A., Rozanov, V. V., Nauss, T., Reudenbach, C., Daniel, J. S., Miller, H. L., and Burrows, J. P.: The semianalytical cloud retrieval algorithm for SCIAMACHY I. The validation, Atmos. Chem. Phys., 6, 1905-1911, doi:10.5194/acp-6-1905-2006, 2006.

Kokhanovsky, A. A., Nauss, T., Schreier, M., von HoyningenHuene, W., and Burrows, J. P.: The intercomparison of cloud parameters derived using multiple satellite instruments, IEEE T. Geosci. Remote, 45, 195-200, doi:10.1109/TGRS.2006.885019, 2007.

Krijger, J. M., van Weele, M., Aben, I., and Frey, R.: Technical Note: The effect of sensor resolution on the number of cloud-free observations from space, Atmos. Chem. Phys., 7, 2881-2891, doi:10.5194/acp-7-2881-2007, 2007.

Lelli, L., Kokhanovsky, A. A., Rozanov, V. V., Vountas, M., Sayer, A. M., and Burrows, J. P.: Seven years of global retrieval of cloud properties using space-borne data of GOME, Atmos. Meas. Tech., 5, 1551-1570, doi:10.5194/amt-5-1551-2012, 2012.

Lichtenberg, G.: Verification Report OL V 5.0, SCIAMACHY Level $1 \mathrm{~b}$ to 2 processing, ENV-VPR-QWG-SCIA-0095, Issue 2, 15 June 2009, available at: http://atmos.caf.dlr.de/sciamachy/ documents/level_1b_2/SCIAVerification_L12_OL5.pdf (last access: 30 September 2013), 2009.

Lichtenberg, G.: SCIAMACHY Offline Processor Levellb-2 ATBD, Algorithm Theoretical Baseline Document (SGP OL Version 5), 23 March 2011, available at: http://atmos.caf.dlr.de/ sciamachy/documents/level_1b_2/sciaol1b2_atbd_master.pdf (last access: 30 September 2013), 2011.

Loyola, D. G.: Automatic cloud analysis from polar orbiting satellites using neural network and data fusion techniques, IEEE T. Geosci. Remote, 4, 2530-2534, doi:10.1109/IGARSS.2004.1369811, 2004. 
Meringer, M.: ENVISAT SCIAMACHY Level $1 \mathrm{~b}$ to 2 Offline processing Input/Output data definition, Doc.No. ENVID-DLR-SCI-2200-4, Issue 5/A, Date 19 January 2010, available at: http://atmos.caf.dlr.de/sciamachy/documents/level_1b_ 2/ioddL12ol_5A.pdf (last acess 8 January 2014), 2010.

Popp, C., Wang, P., Brunner, D., Stammes, P., Zhou, Y., and Grzegorski, M.: MERIS albedo climatology for FRESCO+ O2 A-band cloud retrieval, Atmos. Meas. Tech., 4, 463-483, doi:10.5194/amt-4-463-2011, 2011.

Rothman, L. S., Gordon, I. E., Barbe, A., Benner, D. C., Bernath, P. F., Birk, M., Boudon, V., Brown, L. R., Campargue, A., Champion, J.-P., Chance, K., Coudert, L. H., Dana, V., Devi, V. M., Fally, S., Flaud, J.-M., Gamache, R. R., Goldman, A., Jacquemart, D., Kleiner, I., Lacome, N., Lafferty, W. J., Mandin, J.-Y., Massie, S. T., Mikhailenko, S. N., Miller, C. E., Moazzen-Ahmadi, N., Naumenko, O. V., Nikitin, A. V., Orphal, J., Perevalov, V. I., Perrin, A., Predoi-Cross, A., Rinsland, C. P., Rotger, M., Simeckova, M., Smith, M. A. H., Sung, K., Tashkun, S. A., Tennyson, J., Toth, R. A., Vandaele, A. C., and Vander Auwera, J.: The HITRAN 2008 molecular spectroscopic database, J. Quant. Spectrosc. Ra., 110, 533572, 2009.

Rozanov, V. V. and Kokhanovsky, A. A.: Semianalytical cloud retrieval algorithm as applied to the cloud top altitude and the cloud geometrical thickness determination from top-of-atmosphere reflectance measurements in the oxygen A band, J. Geophys. Res., 109, 5202, doi:10.1029/2003JD004104, 2004.

Rozanov, V. V., Kokhanovsky, A. A., Loyola, D. G., Siddans, R., Latter, B., Stevens, A., and Burrows, J. P.: Intercomparison of cloud top altitudes as derived using GOME and ATSR-2 instruments onboard ERS-2, Remote Sens. Environ., 102, 186-193, doi:10.1109/TGRS.2004.825586, 2006.

Sayer, A. M., Poulsen, C. A., Arnold, C., Campmany, E., Dean, S., Ewen, G. B. L., Grainger, R. G., Lawrence, B. N., Siddans, R., Thomas, G. E., and Watts, P. D.: Global retrieval of ATSR cloud parameters and evaluation (GRAPE): dataset assessment, Atmos. Chem. Phys., 11, 3913-3936, doi:10.5194/acp-11-39132011, 2011.
Sneep, M., de Haan, J. F., Stammes, P., Wang, P., Vanbauce, C., Joiner, J., Vasilkov, A. P., and Levelt, P. F.: Three-way comparison between OMI and PARASOL cloud pressure products, J. Geophys. Res., 113, D15S23, doi:10.1029/2007JD008694, 2008.

Stammes, P.: Spectral radiance modeling in the UV-visible range, in: IRS 2000: Current Problems in Atmospheric Radiation, edited by: Smith, W. and Timofeyev, Y., A. Deepak, Hampton, Va., 385-388, 2001.

Stammes, P., Sneep, M., de Haan, J. F., Veefkind, J. P., Wang, P., and Levelt, P. F.: Effective cloud fractions from the Ozone Monitoring Instrument: theoretical framework and validation, J. Geophys. Res., 113, D16S38, doi:10.1029/2007JD008820, 2008.

Stubenrauch, C. J., Rossow, W. B., Kinne, S., Ackerman, S., Cesana, G., Chepfer, H., Di Girolamo, L., Getzewich, B., Guignard, A., Heidinger, A., Maddux, B., Menzel, P., Minnis, P., Pearl, C., Platnick, S., Poulsen, C., Riedi, J., Sun-Mack, S., Walther, A., Winker, D., Zeng, S., and Zhao, G.: Assessment of Global Cloud Datasets from Satellites: Project and Database Initiated by the GEWEX Radiation Panel, B. Am. Meteorol. Soc., 94, 1031-1049, doi:10.1175/BAMS-D-12-00117.1, 2013.

Wang, P., Stammes, P., van der A, R., Pinardi, G., and van Roozendael, M.: FRESCO+: an improved O2 A-band cloud retrieval algorithm for tropospheric trace gas retrievals, Atmos. Chem. Phys., 8, 6565-6576, doi:10.5194/acp-8-6565-2008, 2008.

Wang, P., Tuinder, O. N. E., Tilstra, L. G., de Graaf, M., and Stammes, P.: Interpretation of FRESCO cloud retrievals in case of absorbing aerosol events, Atmos. Chem. Phys., 12, 90579077, doi:10.5194/acp-12-9057-2012, 2012.

Wielicki, B. A., Wong, T., Loeb, N., Minnis, P., Priestley, K., and Kande, R.: Changes in Earth's albedo measured by satellite, Science, 308, 5723, doi:10.1126/science.1106484, 2005.

Winker, D., Vaughan, M., Omar, A., Hu, Y., Powell, K., Liu, Z., Hunt, W., and Young, S.: Overview of the CALIPSO mission and CALIOP data processing algorithm, J. Atmos. Ocean. Tech., 26, 2310-2323, 2009. 